\title{
Respiratory and Reproductive Paleophysiology of Dinosaurs and Early Birds
}

\author{
John A. Ruben ${ }^{1, \star}$ \\ Terry D. Jones ${ }^{2, \dagger}$ \\ Nicholas R. Geist ${ }^{3, \neq}$ \\ ${ }^{1}$ Zoology Department, Oregon State University, Corvallis, \\ Oregon 97331-2914; ${ }^{2}$ Biology Department, Stephen F. Austin \\ State University, Nacogdoches, Texas 79562-3001; ${ }^{3}$ Biology \\ Department, Sonoma State University, Rohnert Park, \\ California 94928-3609
}

Accepted 1/24/03

\section{ABSTRACT}

In terms of their diversity and longevity, dinosaurs and birds were/are surely among the most successful of terrestrial vertebrates. Unfortunately, interpreting many aspects of the biology of dinosaurs and the earliest of the birds presents formidable challenges because they are known only from fossils. Nevertheless, a variety of attributes of these taxa can be inferred by identification of shared anatomical structures whose presence is causally linked to specialized functions in living reptiles, birds, and mammals. Studies such as these demonstrate that although dinosaurs and early birds were likely to have been homeothermic, the absence of nasal respiratory turbinates in these animals indicates that they were likely to have maintained reptile-like (ectothermic) metabolic rates during periods of rest or routine activity. Nevertheless, given the metabolic capacities of some extant reptiles during periods of elevated activity, early birds were probably capable of powered flight. Similarly, had, for example, theropod dinosaurs possessed aerobic metabolic capacities and habits equivalent to those of some large, modern tropical latitude lizards (e.g., Varanus), they may well have maintained significant home ranges and actively pursued and killed large prey. Additionally, this scenario of active, although ectothermic, theropod dinosaurs seems reinforced by the likely utilization of crocodilian-like, diaphragm breathing in this group. Finally, persistent in vivo burial of their nests and ap-

\footnotetext{
*E-mail: rubenj@science.oregonstate.edu.

† E-mail: tdjones@sfasu.edu.

‡ E-mail: nick.geist@sonoma.edu.
}

Physiological and Biochemical Zoology 76(2):141-164. 2003. (C) 2003 by The University of Chicago. All rights reserved. 1522-2152/2003/7602-2131\$15.00 parent lack of egg turning suggests that clutch incubation by dinosaurs was more reptile- than birdlike. Contrary to previous suggestions, there is little if any reliable evidence that some dinosaur young may have been helpless and nestbound (altricial) at hatching.

\section{Introduction}

A suite of morphological attributes suggests that dinosaurs and birds are close relatives, and their patterns of evolution have long been the subject of intense study and speculation (Feduccia 1999b). In many respects, dinosaurs were the most dominant of the archosaurs (including but not limited to dinosaurs, crocodilians, birds, and pterosaurs), and they were probably among the most successful of all the land vertebrates. Their $150+$ million year cosmopolitan reign over the terrestrial environment (from Late Triassic to Late Cretaceous Periods of the Mesozoic Era, ca. $220+$ to 65 Myr) far exceeds the duration and magnitude of dominance by any other group of tetrapods, including the mammals and their ancestors. Most notably, dinosaur diversity, including the Saurischia and Ornithischia, was spectacular, and their variety encompassed some of the most specialized vertebrates ever to have existed.

Birds date back at least to the famous archaeornithine $\mathrm{Ar}$ chaeopteryx lithographica ( $145 \mathrm{Myr}$, Late Jurassic), and powered flight, combined with great endurance and endothermy in extant birds, has enabled birds to reach and thrive on all the continents and oceans. Like the dinosaurs, birds are surely among the most successful terrestrial vertebrates, in terms of both their diversity and worldwide population numbers.

Few, if any, other aspects of the biology of dinosaurs and early birds have sparked more recent interest or controversy than have attempts to decipher their activity patterns and metabolic and reproductive biology. For example, the popular notion that dinosaurs, like living mammals and birds, may have been endothermic provides a model that reinforces interpretation of these animals as having led particularly active, interesting lives. The more traditional model, that dinosaurs were ectothermic, is often incorrectly associated with dull beasts leading slothful, sedentary lives.

Regardless of how one might wish to recreate the life histories of dinosaurs or early birds, accurate interpretation of the evo- 
lutionary history of any group of animals necessitates that careful, objective evaluation of appropriate data be considered. Such has not always been the rule. Instead, "the strongest impression gained from reading the literature of the dinosaur [metabolic] physiology controversy is that some of the participants have behaved more like politicians or attorneys than scientists, passionately coming to dogmatic conclusions via arguments based on questionable assumptions and/or data subject to other interpretations" (Farlow 1990, pp. 43-44). In addition, significant peer pressure to interpret morphology, physiology, and/or behavior of extinct taxa primarily by reliance on cladograminferred relationships has been noted elsewhere (Feduccia 1999a; Dodson 2000; Padian and Horner 2002). However, as Westoby et al. (1995, p. 532) point out, heavy reliance on cladograms as paleobiological guides largely ignores the interaction between ecology and phylogeny and is merely "a conceptual decision to give priority to one interpretation over another."

Rather, we suggest that in many cases there is greater utility in evaluation of biological attributes in ancient forms on a caseby-case basis. More specifically, it may often be more revealing to examine extinct taxa with a view toward identification of diagnostic, derived (apomorphic) structures that are causally linked to specialized processes or lifestyles in related, living taxa. Thus, rather than starting with the a priori assumption that dinosaurs were endothermic or that they possessed other apomorphic attributes like those of modern birds, we suggest it is preferable to assume the presence of the primitive amniote condition (e.g., ectothermy, biphasic breathing) and then attempt to falsify that assumption by identification of derived morphological features in dinosaurs that are causally or functionally linked to endothermy or air-sac breathing in living taxa.

Here we present recent evidence for respiratory and reproductive biology in dinosaurs and the earliest birds. In both cases, we have considered the shared presence or absence of diagnostic, derived morphological features in extinct and related extant forms to be the best indicators of respiratory and reproductive patterns in taxa known only from fossils.

\section{Metabolism and Thermoregulation in Amniotes, Living and Extinct}

Variation in metabolic rate, especially during periods of rest or routine activity, comprises the core physiological difference between ectotherms (e.g., reptiles) and endotherms (birds, mammals). Endotherms routinely have much higher rates of aerobiosis or cellular oxygen consumption: at rest, mammalian and avian metabolic rates are typically about five to 15 times greater than those of reptiles of the same body mass and temperature (Bennett 1973b, 1982, 1991; Bennett and Dawson 1976; Else and Hulbert 1981; Schmidt-Neilsen 1984, 1990). In the field, the metabolic rates of mammals and birds typically exceed reptilian rates by about 20 times (Nagy 1987). Clearly, en- dothermy is one of the major evolutionary milestones of vertebrates and is among the most significant features that distinguish living birds and mammals from reptiles, amphibians, and fish. Endothermy, which evolved independently in birds and mammals (Kemp 1988), provides these organisms with distinct physiological and ecological benefits and may be largely responsible for the present success of birds and mammals in a wide range of aquatic and terrestrial environments. As discussed below, elevated rates of lung ventilation, oxygen consumption, and internal heat production enable birds and mammals to maintain thermal stability over a wide range of ambient temperatures. As a result, endotherms are able to thrive in environments with cold or highly variable thermal conditions and in many nocturnal niches generally unavailable to ectothermic vertebrates. Furthermore, the increased aerobic capacities of endotherms allow them to sustain routine activity levels well beyond the capacity of most ectotherms. With some noteworthy exceptions, ectotherms such as reptiles typically rely on nonsustainable, anaerobic metabolism for all activities beyond relatively slow movements. Although capable of often spectacular bursts of intense exercise, ectotherms generally fatigue rapidly as a result of lactic acid accumulation. Alternatively, endotherms are able to sustain even relatively high levels of activity for extended periods. This enables these animals to forage widely and to migrate over extensive distances (Bennett and Ruben 1979; Ruben 1995).

Thermoregulatory strategies in extant endothermic and ectothermic tetrapods also contrast sharply with one another. During periods of either routine or accelerated levels of activity in endotherms, internal heat production rates are usually sufficient to enable them to maintain a constant body temperature over a wide range of ambient temperatures. Alternately, without access to a substantive external heat source (e.g., the sun), ectotherms, especially those of temperate latitudes, are generally unable to achieve and maintain optimal body temperatures. In such cases, $Q_{10}$ effects often cause ectotherms to appear sluggish, even in moderate temperatures. These contrasting thermoregulatory attributes formed much of the basis for the early reconstructions of "cold-blooded," brutish, slow-moving dinosaurs, but they were also the impetus for notions of endotherm superiority and the popular appeal of "hot-blooded" dinosaurs (e.g., Bakker 1968, 1975, 1980).

In reality, low resting metabolic rates typical of extant ectotherms hardly preclude their frequent maintenance of high body temperatures and/or homeothermy during periods of activity. Given normal field conditions, many extant reptiles maintain marked variation between internal and external temperatures (Pearson 1954; Schmidt-Neilsen 1990). Even small lizards of temperate latitudes are often sufficiently adept at solar basking that they sustain diurnal body temperatures that overlap or, in some cases, exceed those of many endotherms (Greenberg 1980; Avery 1982). In addition, some particularly large ectotherms (e.g., Komodo dragons [Varanus]) living in warm, 
equable climates remain virtually homeothermic for long periods in their natural environments. In such cases, these animals achieve "inertial homeothermy" by virtue of their minimal surface-area-to-volume ratios and correspondingly low heat loss rates (Frair et al. 1972; McNab and Auffenberg 1976; Standora et al. 1984; Paladino et al. 1990).

Given the generally warm, equable climates of the Mesozoic Era, behavioral thermoregulation and thermal inertia were likely to have enabled dinosaurs, whether ecto- or endothermic, to have maintained relatively high and stable body temperatures for extended periods of time. Mathematical models indicate that medium-sized to large dinosaurs ( $>500 \mathrm{~kg}$; some sauropods probably exceeded $30,000 \mathrm{~kg}$ ) were likely to have been inertial homeotherms, relatively unaffected by diurnal temperature fluctuations (Spotila et al. 1991; Paladino et al. 1997; O'Conner and Dodson 1999; Seebacher et al. 1999). In such cases, even small fluctuations in body temperatures might have occurred only on a weekly or monthly scale. As in many extant reptiles, small dinosaurs $(<75 \mathrm{~kg})$ might easily have utilized behavioral thermoregulation to achieve high body temperatures and homeothermy during periods of diurnal activity. Interestingly, at high latitudes during the Late Cretaceous Era, some dinosaurs might have resorted to hibernation or migration to escape seasonal cooling. These models indicate that dinosaurs were quite capable of maintaining high and stable body temperatures regardless of their metabolic status, and the dynamic skeletal structures of many dinosaurs strongly suggest that they possessed bird- or mammal-like capacity for at least burst activity. Thus, even if fully ectothermic, had dinosaurs possessed aerobic metabolic capacities and activity patterns equivalent to those of some large, modern tropical latitude lizards (e.g., Varanus), they may well have maintained large home ranges, actively pursued and killed large prey, escaped predators, and defended themselves fiercely (Bennett 1973a).

Another variable that impacts resting or routine metabolic rate in all organisms is body mass. Because of their greater mass, large ectotherms and endotherms maintain higher total metabolic rates than do small ectotherms and endotherms, respectively. However, because of the allometric relationship between body mass and metabolic rate (where total metabolic rate scales at about body mass ${ }^{0.75}$ ), each gram of tissue in a small animal actually sustains a higher rate of oxygen consumption than does each gram of tissue in a larger animal. Thus, while a resting elephant obviously maintains a much higher rate of total calorie production than does a resting mouse, each gram of mouse has an oxygen consumption rate considerably greater than does each gram of elephant. The physiological mechanisms and selective factors governing the allometry of metabolism have long puzzled biologists (SchmidtNeilsen 1990; Darveau et al. 2002; Randall et al. 2002), but the relationship between body mass and metabolic rate is well documented for all vertebrate and invertebrate classes (Hemmingsen 1960). Similar allometry almost surely occurred in dinosaurs as well (Reid 1997). However, by itself, this metabolic scaling has no implication for interpreting the ectothermic or endothermic status of dinosaurs (Reid 1997): as a result of their lower mass, small ectothermic dinosaurs undoubtedly would have maintained considerably higher mass-specific metabolic rates than would larger dinosaurs. Therefore, all other factors being equal, smaller ectothermic dinosaurs were no closer to achieving avian metabolic rates than were large dinosaurs. Similarly, large extant birds and mammals are not less endothermic than are small ones, and small extant reptiles are no closer to an endothermic metabolic status than are larger species.

Given the significance of metabolic status to the lifestyles of extant vertebrates, it is hardly surprising that identification and elaboration of physiological parameters associated with vertebrate ecto- and endothermy have received so much attention in the last 4 decades (Bennett 1991). However, although by itself the physiology of extant taxa usually provides little, if any, historical perspective into the metabolic status of long extinct taxa, correlations between physiology and morphology can be extremely valuable in this regard.

Until very recently, endothermy has been virtually impossible to demonstrate clearly in extinct forms. Endothermy is almost exclusively an attribute of the "soft anatomy," which usually leaves a poor or nonexistent fossil record. To support their high oxygen consumption levels, endotherms possess profound structural and functional modifications to facilitate oxygen uptake, transport, and delivery. Both mammals and birds have greatly expanded rates of lung ventilation, fully separated pulmonary and systemic circulatory systems, and expanded cardiac output. They also have greatly increased blood volume and blood oxygen-carrying capacities, as well as increased tissue aerobic enzymatic activities (Ruben 1995). Unfortunately, these key features of endothermic physiology are unlikely to have ever been preserved in fossils-mammalian, avian, or otherwise.

Consequently, previous hypotheses concerning possible endothermy in a variety of extinct vertebrates, especially dinosaurs, have relied primarily on supposed correlations of metabolic rate with a variety of weakly supported criteria (including, but not limited to, predator-to-prey ratios, fossilized trackways, correlations with avian or mammalian posture, and so on; e.g., Bakker 1971, 1980, 1986). Close scrutiny has revealed that virtually all of these correlations are, at best, equivocal (Bennett and Dalzell 1973; Farlow et al. 1995).

More recently, conjecture regarding possible dinosaur endothermy has often centered on the assumed relationship of bone histology to growth rates in ecto- and endotherms. Two histological types of compact bone have been recognized in extant vertebrates, differing qualitatively in their fibril organization and degree of vascularization. The primary bone of extant amphibians and most reptiles is lamellarzonal. Here, compact bone is deposited in relatively few primary osteons, principally by periosteal deposition. Histologically, lamellar- 
zonal bone has a layered appearance, within which incremental growth lines are often recognized; it is also poorly vascularized. Conversely, the fibrolamellar bone of many birds, mammals, and dinosaurs is well vascularized, and most of the bony matrix is deposited in abundant primary osteons that produce a fibrous, woven appearance (Reid 1997).

Lamellarzonal bone has been associated with ectothermy and fibrolamellar with endothermy. Fibrolamellar bone is often held to be correlated with high growth rate that requires rapid deposition of calcium salts. Such rapid growth is supposedly possible only in systems with the elevated metabolic rates associated with endothermy. Thus, the primary correlation is supposedly between growth rate and bone structure. Accordingly, it has been widely accepted that growth rates of extant endotherms in the wild are about an order of magnitude greater than in ectotherms. Given the widespread occurrence of fibrolamellar bone in dinosaurs, their growth is often assumed to have been rapid, as in birds and mammals. According to this scenario, like mammals and birds, they must also have been endothermic, or nearly so (Chinsamy and Dodson 1995; Reid 1997; Padian and Horner 2002).

Much of this scenario is inconsistent with a variety of paleontological and biological data. Reptiles are able to form fibrolamellar bone, which suggests that a high basal metabolic rate is not a prerequisite for such bone deposition (contra Horner et al. 2001b; Padian and Horner 2002). For example, fibrolamellar bone is known to be present in the skeleton of extant, rapidly growing turtles, crocodilians, and lizards (Chinsamy and Dodson 1995; Reid 1997). Moreover, long bones in numerous dinosaurian genera have regions of both fibrolamellar and lamellarzonal histology (Chinsamy and Dodson 1995; Reid 1997). In addition, during the early stages of development when relative growth rates are highest in virtually all tetrapods, fibrolamellar bone is often formed, but, paradoxically, this is also the stage when particularly fast-growing altricial avian hatchlings are poikilothermic ectotherms (Ricklefs 1979; Olson 1992; Thomas et al. 1993; Visser and Ricklefs 1993; Dietz and Drent 1997).

In any case, attempts to assess growth rates in extinct archosaurs using bone histology as an indicator of bone depositional rates (Horner et al. 2001b) are probably futile. Starck and Chinsamy (2002, p. 241) have demonstrated that under experimentally varied environmental and/or nutritional regimes, bone growth rate variation is sufficiently large "that extrapolations of average bone deposition rates from extant birds to fossil dinosaurs [e.g., Horner et al. 2000] are premature and inaccurate." Clearly, since bone depositional rates have not been linked to actual oxygen consumption rates and basal metabolic rates, it is inappropriate to directly deduce aspects of metabolic physiology (e.g., endothermy vs. ectothermy) from bone texture and organization (Chinsamy 1994; Chinsamy and Hillenius, in press).

Bone histology notwithstanding, there is also reason to ques- tion the presumed magnitude of variation in growth rates between endotherms and nonavian sauropsids, especially crocodilians, the closest living relatives of birds and dinosaurs. In the most frequently cited comparative study, regressions for maximal sustained growth rates (g/day) for amniotes scaled positively with increasing adult body mass (slope $<0.7$ ), but reptile $Y$-intercept elevations ("a" values) were reportedly only about $10 \%$ those of endotherms (Case 1978). However, criteria for calculating these regressions were not equivalent: endotherm "adult weight" approximated mass at sexual maturity, and mass at a similar stage in the ectotherm life cycle would seem appropriate to facilitate construction of regressions on an equal-footing basis. Nevertheless, American alligator (Alligator mississippiensis) "adult weight" was plotted at $160 \mathrm{~kg}$, a value far in excess of the species' actual 30-kg mass at sexual maturity. In addition, growth rate for the alligator was listed at $28 \mathrm{~g} / \mathrm{d}$ rather than the more accurate $42 \mathrm{~g} / \mathrm{d}$ (T. J. Case, personal communication). If the corrected daily growth increment, as well as the more appropriate $30-\mathrm{kg}$ mature mass, is assumed, growth rate for the American alligator is actually about fourfold that of marsupials and approximates growth rates in many placental mammals (Ruben 1995). In this context, it is especially significant that growth rates in some alligators are virtually indistinguishable from estimated growth rates for the dromaeosaurid theropod dinosaur Troodon (Ruben 1995). Additionally, Chinsamy and Dodson (1995) evaluated growth rate in three genera of dinosaurs and found no broad pattern of elevated growth rates.

In another scenario, relative quantities of fossilized bone oxygen isotope $\left(\mathrm{O}^{16}: \mathrm{O}^{18}\right)$ were purported to demonstrate relatively little in vivo variation between extremity and deep body temperature in some large dinosaurs (e.g., Tyrannosaurus; Barrick and Showers 1994). This was assumed to signify that these large dinosaurs were endothermic, since living endotherms, unlike ectotherms, were presumed to maintain relatively uniform extremity versus core temperatures. However, there are abundant data demonstrating that many birds and mammals often maintain extremity temperatures well below deep-body, or core, temperatures (Ruben 1995). Additionally, fossil bone oxygen isotope ratios may be strongly influenced by ground water temperatures (Kolodny et al. 1996) and, in any case, the conclusions reached by Barrick and Showers (1994) are not statistically supported by their own data (Ruxton 2000). Fossilized bone oxygen isotope ratios in dinosaurs are likely to reveal little, if any, definitive information about dinosaur metabolic physiology.

Fisher et al. (2000) describe evidence of what they claim is a fossilized four-chambered heart with a fully partitioned ventricle in an onithischian dinosaur, Thescelosaurus. These authors assert that, as in birds, the fossilized heart lacked a foramen of Panizza between the ventricles and had a single aortic trunk. They also suggest that these attributes are consistent with a high, perhaps endotherm-like, metabolic rate in this dinosaur. 
Unfortunately, several anatomical errors and questionable assumptions cast serious doubts on this interpretation.

Contrary to Fisher et al. (2000), the ventricles of extant crocodilians are, as in birds, fully separated. Moreover, the foramen of Panizza is located not between the ventricles but at the base of the aortic trunks (Goodrich 1930; White 1968, 1976; Franklin et al. 2000). A fully partitioned, four-chambered heart is thus present in both crocodilians and birds, and not only was its presence among dinosaurs likely, but it also affords little inference regarding metabolic rates in these animals. The presence of a single aortic trunk (rather than the paired aortic trunks of extant reptilians) might be more diagnostic. However, it is clear that the cardiovascular complex of this specimen is incomplete since neither the pulmonary arteries nor the carotids are preserved (Fisher et al. 2000). Thus, the presence in life of only a single aortic trunk cannot be substantiated. Significantly, the left side of the specimen (where the "missing" aortic trunk would most likely have been) is absent from the fossil. Finally, it remains unclear if the specimen is actually a fossilized heart or merely an artifact (Rowe et al. 2001). This specimen seems to provide little, if any, reliable insight into the metabolic physiology of dinosaurs.

Recently, filiform, feather, or feather-like integumentary structures have been described in a variety of small theropod specimens from Early Cretaceous deposits in China. These have been interpreted by some as evidence that theropod dinosaurs possessed an insulative covering, suggestive of endothermic homeothermy. However, the presence of even a fully developed set of feathers in dinosaurs or even in the Mesozoic avian ancestors of extant birds need not necessarily signal the presence of endothermy or even an approach to it. Like modern reptiles, some living birds utilize behavioral thermoregulation to absorb ambient heat across feathered skin. During nocturnal periods of low ambient temperatures, body temperature in the roadrunner (Geococcyx californianus) declines by $\sim 4^{\circ} \mathrm{C}$. After sunrise, the roadrunner exposes poorly feathered parts of its body to solar radiation and warms ectothermically to normal body temperature (Ohmart and Lasiewski 1971). Additionally, a number of other fully feathered extant birds can readily absorb and use incident radiant solar energy (e.g., Hamilton and Heppner 1966; Lustick et al. 1970). Similarly, feathered ectothermic theropods, which are thought to have lived in a warm sunny climate, might easily have had similar behavioral thermoregulatory capacity. Indeed, even a fully feathered Archaeopteryx, whether ectothermic or endothermic, could easily have achieved homeothermy. Consequently, the appearance of plumage or plumage-like covering in theropods or early birds need not have been linked to any particular pattern of metabolic physiology. Finally, since feather antecedents are likely to have appeared initially in small, gliding archosaurs from the middle Triassic Period (220 Myr; Fig. 1; Geist and Feduccia 2000; Jones et al. 2000, 2001), the function of feathers or feather-like integumentary structures in dinosaurs is problematic.
Perhaps more to the point, virtually all of the previous arguments are based predominantly on apparent similarities to the mammalian or avian metabolic condition, without a clear functional correlation to endothermic processes per se. Until recently, no empirical studies were available that described an unambiguous and exclusive functional relationship to endothermy of a preservable morphological characteristic. However, respiratory turbinates are essential to, and have a tight functional correlation with, maintenance of high rates of lung ventilation and metabolism in virtually all terrestrial mammals. It has also been discovered that respiratory turbinates and, presumably, elevated lung ventilation and metabolic rates occurred in at least two groups of Permo-Triassic mammal-like reptiles (therapsids; Hillenius 1992, 1994). Consequently, the respiratory turbinates represent the first direct morphological indicator of endothermy that can be observed in the fossil record.

\section{Respiratory Turbinates in Living Endotherms}

Turbinate bones, or cartilages, are scroll- or baffle-like elements located in the nasal cavity of all reptiles, birds, and mammals. In most mammals, these usually consist of two sets of mucous membrane-lined structures that protrude directly into either the main nasal airway or blind "alleyways" immediately adjacent to the main respiratory airway (Fig. 2). Those situated directly within the main anterior nasal air passageway (i.e., the nasal passage proper), the maxilloturbinates or respiratory turbinates, are thin, complex structures lined with moist respiratory epithelia. Olfactory turbinates (lateral sphenoids, nasoor ethmoturbinates) are located just out of the main path of respired air, usually dorsal and posterior to the main nasal passage. Olfactory turbinates are lined with olfactory (sensory) epithelia that contain the primary receptors for the sense of smell; they occur ubiquitously in all reptiles, birds, and mammals and have no association with the maintenance of endothermy (Hillenius 1992, 1994).

Only the respiratory turbinates have a strong functional association with endothermy. In both mammals and birds, endothermy is tightly linked to high levels of oxygen consumption and elevated rates of lung ventilation (e.g., avian and mammalian metabolic and lung ventilation rates in the field exceed reptilian rates by about 20 times [Nagy 1987]). Respiratory turbinates create an intermittent countercurrent exchange of respiratory heat and water between respired air and the moist, epithelial linings of the turbinates (Fig. 3). Briefly, as cool external air is inhaled, it absorbs heat and moisture from the turbinate linings. This prevents desiccation of the lungs, but it also cools the respiratory epithelia and creates a thermal gradient along the turbinates. During exhalation, this process is reversed: warm, fully saturated air from the lungs is cooled as it passes back over the respiratory turbinates. The exhaled air becomes supersaturated as a result of this cooling, and "excess" water vapor condenses on the turbinate surfaces, where it can 


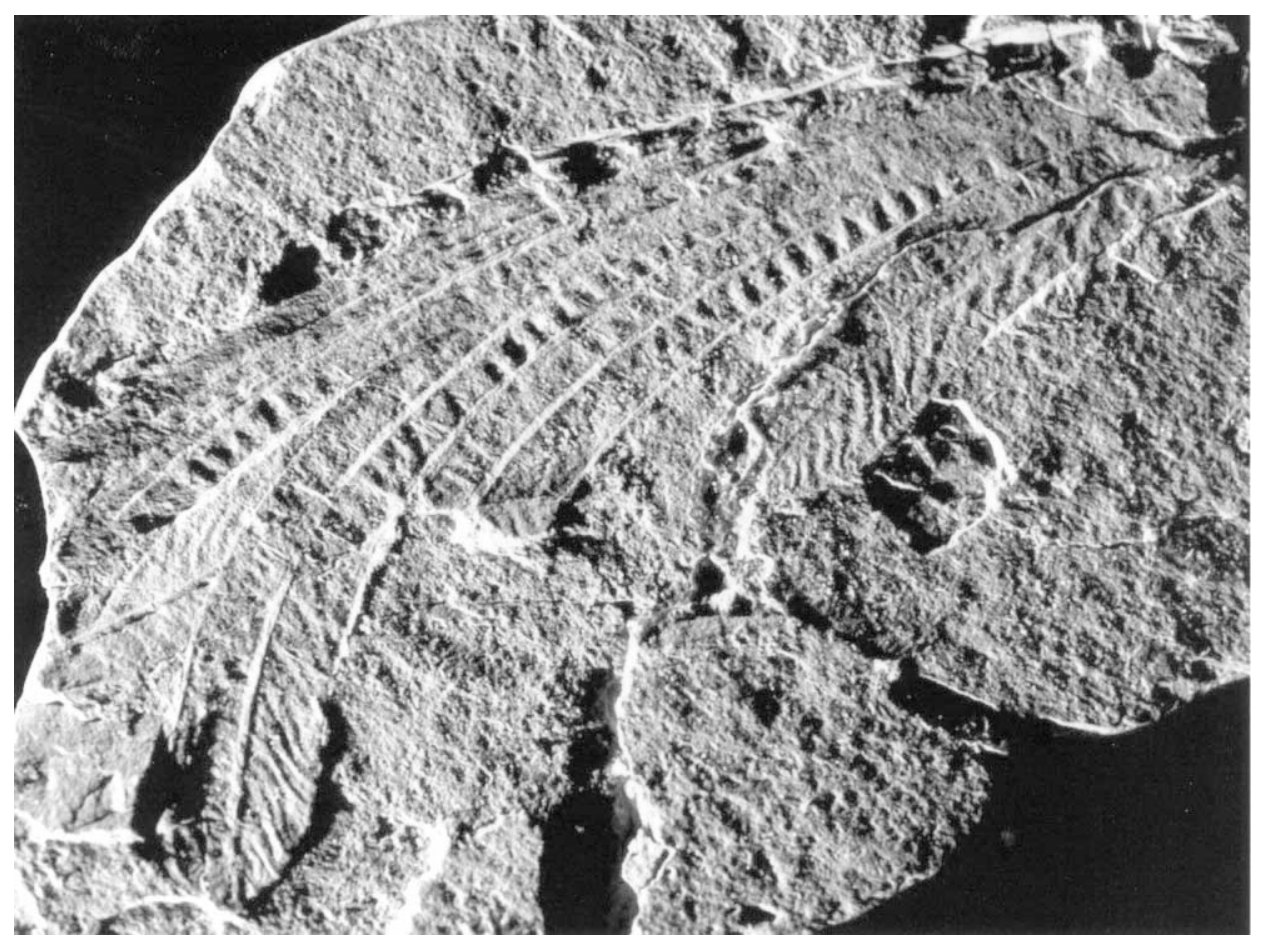

Figure 1. Nonavian feathers from the Middle Triassic Longisquama, a small archosaur that predated the earliest dinosaurs. As in modern feathers, and unlike scales, these structures developed in follicles and were hollow (Jones et al. 2000). Assertions elsewhere that these elements were merely elongate, bladelike scales (Prum 2001) are falsified by the overlapped position of some individual barb elements. Longisquama was probably an accomplished glider, but the function of feathers or feather-like structures in dinosaurs remains unclear.

be reclaimed and recycled. Over time, a substantial amount of water and heat can thus be conserved rather than lost to the environment (Fig. 3). In the absence of respiratory turbinates, continuously high rates of oxidative metabolism and endothermy might well be unsustainable insofar as respiratory water and heat loss rates would frequently exceed tolerable levels, even in species of nondesert environments (Hillenius 1992; Ruben 1996; Geist 2000). Additionally, it has long been suggested that the ubiquitous occurrence of vascular shunts between respiratory turbinates and the brain indicates that these turbinates are also utilized as brain "coolers." This would be especially critical during periods of elevated ambient temperatures or during periods of extended activity typical of many birds and mammals, when rates of internal heat production would be highest (Baker 1982; Bernstein et al. 1984).

Respiratory turbinates are present in all extant nostrilbreathing terrestrial birds and mammals (Hillenius 1994; Ruben et al. 1996). The extent and complexity of the nasal cavity of birds vary with bill shape but, in general, the avian nasal passage is elongate with three successive cartilaginous or (occasionally) ossified turbinates (Bang 1971; Fig. 2). The anterior turbinate is often relatively simple, but the others, particularly the middle turbinates, are usually highly developed as prominent scrolls with multiple turns. Sensory (olfactory) epithelium is restricted to the posterior turbinate. As in mammals, the olfactory turbinates are situated outside the main respiratory air stream, often in a separate chamber. Embryological and anatomical studies indicate that only the posterior turbinate is homologous to those of reptiles; the anterior and middle turbinates have evolved independently in birds (Witmer 1995).

The anterior and middle turbinates of birds, like the respiratory turbinates of mammals, are situated directly in the nasal passage and are covered primarily with respiratory epithelium. These turbinates are well positioned to modify bulk respired air. Previously published observations demonstrate that the respiratory turbinates of birds function as well as, or superior to, those of mammals for the recovery of water vapor contained in exhaled air (Geist 2000). Consequently, in birds, these structures probably represent an adaptation to high lung ventilation rates and endothermy, fully analogous to respiratory turbinates of mammals.

Neither mammalian nor avian respiratory turbinates have analogs or homologs among living reptiles or amphibians (Witmer 1995). In living reptiles, one to three simple nasal turbinates are typically located in the posterodorsal portion of the nasal cavity and, like those of mammals and birds, are exclusively olfactory in function (Fig. 2). There are no structures in the reptilian nasal cavity (or the nasal cavity of any extant 


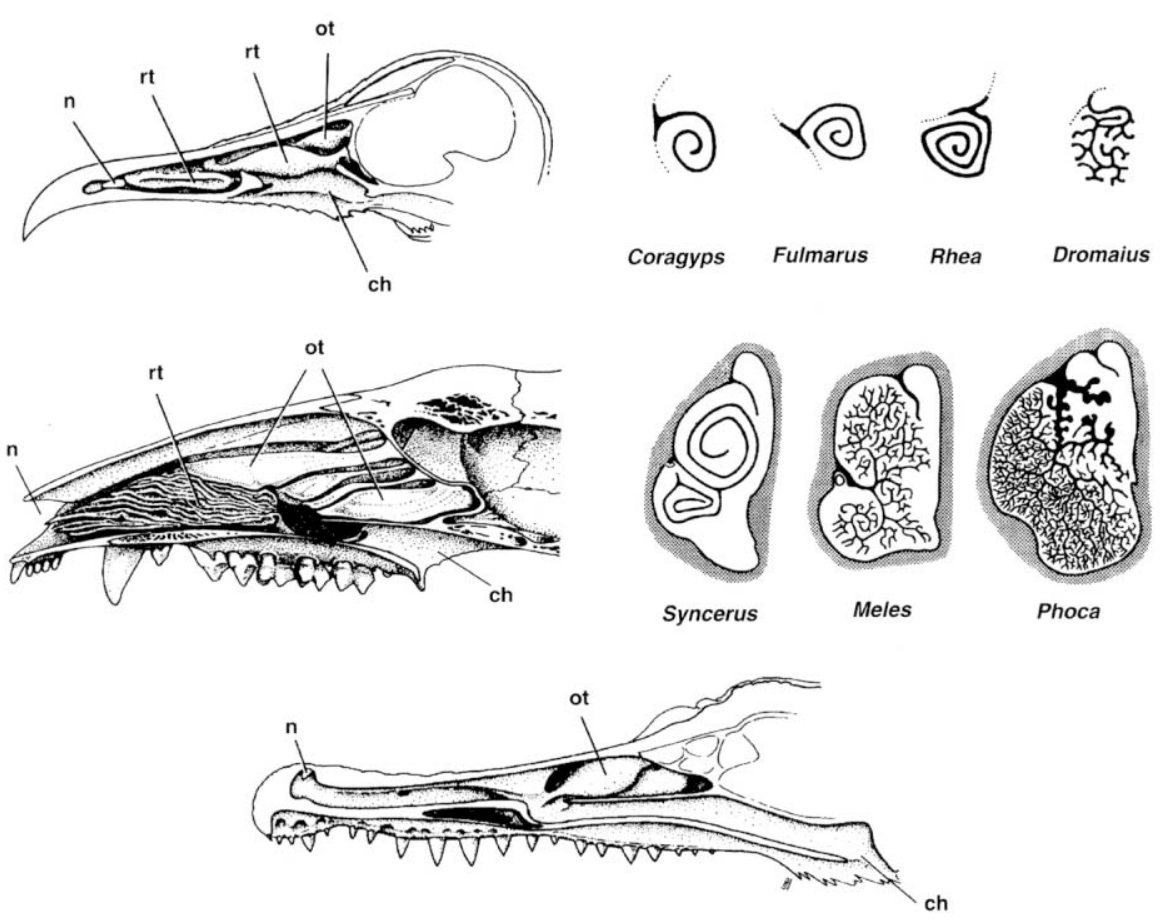

Figure 2. Nasal passage anatomy in modern birds (top left), mammals (middle left), and crocodilians (bottom); representative cross sections through respiratory turbinates in living birds (top right) and mammals (middle right). Abbreviations: $n=$ nostrils; $r t=$ respiratory turbinate; $o t=$ olfactory turbinate; $c h=$ choana or internal nares. Modified from Hillenius (1994).

ectotherm) specifically adapted for the recovery of respiratory water vapor, nor are they as likely to be needed. Reptilian lung ventilation rates are apparently sufficiently low that respiratory water loss rates seldom create significant problems, even for desert species.

Maintenance of an analogous countercurrent exchange mechanism in any portion of the respiratory tree other than the nasal cavity would be untenable; such exchange sites in the body cavity would necessarily preclude deep-body homeothermy, while the presence of such a system in the trachea would interfere with the stability of brain temperatures due to the proximity to the brain-bound carotid arteries (Ruben et al. 1997b; Jones and Ruben 2001). The fact that deep nasopharyngeal temperature is equivalent to core body temperature in extant mammals (Ingelstedt 1956; Jackson and Schmidt-Neilsen 1964; Proctor et al. 1977) and birds (Geist 2000) confirms that little or no heat exchange takes place in the trachea. Finally, the widespread presence of respiratory turbinates among extant mammals and birds also indicates that these structures are likely a plesiomorphic attribute for each of these groups (Hillenius 1992, 1994; Geist 2000); the rare cases of turbinate reduction or absence among these taxa clearly represent secondary, specialized developments.

To summarize, physiological data denote that independent selection for endothermy in birds, mammals, and/or their an- cestors was, by necessity, tightly associated with the convergent evolution of respiratory turbinates in these taxa. In the absence of these structures, unacceptably high rates of respiratory water and heat loss and/or central nervous system overheating would probably have posed chronic obstacles to maintenance of elevated rates of bulk lung ventilation or high, sustained levels of activity consistent with endothermy. Although independently derived in avians (Witmer 1995), these structures are remarkably similar to their mammalian analogs, and a variety of data confirm that avian respiratory turbinates have a similar functional association with high lung ventilation rates and endothermy. Consequently, as in the therapsid-mammal lineage, the occurrence or absence of these structures provides a potential "road map" for revealing patterns of lung ventilation rate and metabolism in early birds and their close relatives, the dinosaurs.

\section{Respiratory Turbinates and the Metabolic Status of Dinosaurs and Early Birds}

Several factors complicate the study of the evolutionary history of turbinates in birds and, potentially, in their relatives, the dinosaurs. Although they ossify or calcify in many extant taxa, these structures often remain cartilaginous and lack bony points of contact in the nasal passage of birds, thus greatly decreasing 

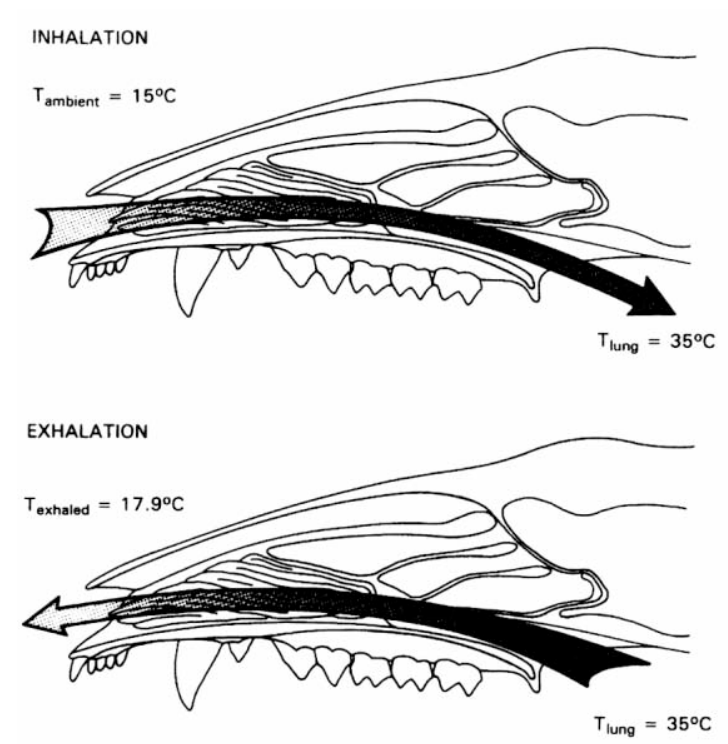

Figure 3. Countercurrent heat exchange mechanism of the respiratory turbinates. During inhalation, air is warmed to body temperature and saturated with water vapor as it passes over the respiratory turbinates. As a result, turbinate surfaces are cooled by evaporative heat loss. On exhalation, the process is reversed as warm, saturated air from the lungs passes over cool turbinate surfaces. As a result, exhaled air becomes supersaturated with water vapor, and excess moisture condenses on and warms the surfaces of the turbinates.

the chances for direct detection of their presence or absence in extinct taxa. Nevertheless, the presence of respiratory turbinates in extant endotherms is inevitably associated with marked expansion of the proportionate cross-sectional area of the nasal cavity proper (Ruben et al. 1996; Fig. 4). Increased nasal passage cross-sectional area in endotherms probably serves to accommodate elevated lung ventilation rates and to provide increased rostral volume to house the respiratory turbinates. Significantly, relative nasal passage diameter in a sequence of therapsids (the immediate ancestors of mammals) approaches and, in the very mammal-like Thrinaxodon, even attains mammalian/avian nasal passage cross-sectional proportions (Fig. 4).

The application of computed tomography (CT) scans to paleontological specimens has greatly facilitated noninvasive study of fine details of the nasal region in fossilized specimens, especially those that have been "incompletely" prepared. In the theropod Nanotyrannus (Fig. 5), CT scans clearly demonstrate that in life this animal was unlikely to have possessed respiratory turbinates: they are absent from the fossil, and nasal passage cross-sectional dimensions are identical to those in extant ectotherms (Figs. 4, 5). Additionally, CT scans of the nasal region of another theropod dinosaur, the ornithomimid theropod Ornithomimus, indicate the presence of narrow, ectotherm-like nasal cavities unlikely to have housed respiratory turbinates
(Figs. 4, 5). This condition is strikingly similar to the nasal region of many extant reptiles (e.g., Crocodylus, Figs. 2, 4).

The ornithischian hadrosaur Hypacrosaurus had a similar narrow, ectotherm-like nasal passage (Figs. 4, 5) and, as in the nasal passages of the theropod dinosaurs, was unlikely to have contained respiratory turbinates (Ruben et al. 1996). The upper end of the nasal passage of lambeosaurines, including that of Hypacrosaurus, consisted of a complex of diverticula and curved passages (Weishampel 1981b), but these appear to relate to sound production (Weishampel 1981a, 1997) and possibly to olfactory functions (Horner et al. 2001a).

Extensive modifications of the narial region, resulting in occasionally marked expansion of the nostrils (narial fossae), do occur, however, in some other ornithischians (e.g., ceratopsids, hadrosaurine ornithopods) and in some sauropod dinosaurs (e.g., brachiosaurs; Witmer 1999). The function of narial expansion in these dinosaurs remains unclear, and each case appears to be an independently derived specialization, absent in the smaller, basal members of each taxon (e.g., Dodson and Currie 1990; Forster 1990; Weishampel et al. 1993; Upchurch 1995). Thus, without specific compelling evidence to the contrary, there is no particular reason to suspect that the expanded narial regions in these particular dinosaurs are associated with elevated resting metabolic and lung ventilation rates.

Unfortunately, nasal passage cross-sectional area can only be accurately quantified in three-dimensionally preserved skulls; therefore, this parameter offers little insight into the metabolic status of many archosaurians, especially early birds. However, pneumatization of the skull and, in particular, the morphology of the paranasal (accessory) sinuses ( $A C$ in Fig. 5) make it

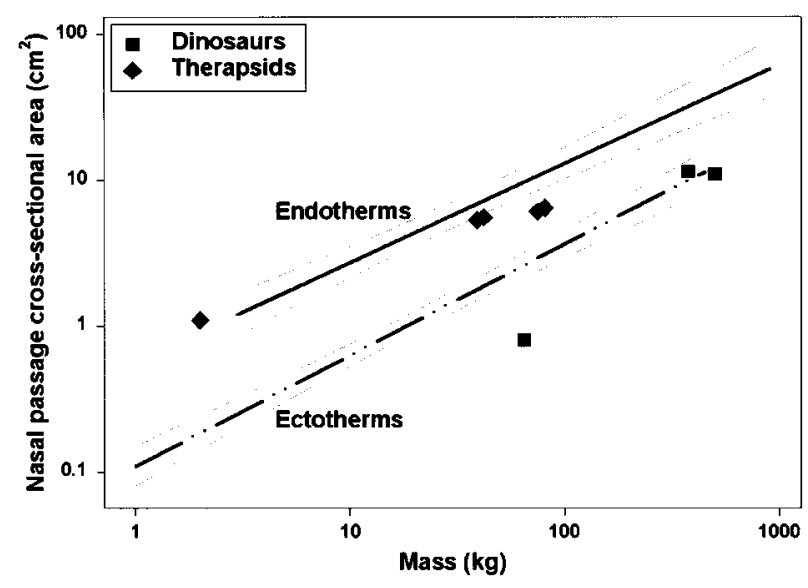

Figure 4. Relationship of nasal passage cross-sectional area to body mass (M) in extant endotherms (birds and mammals; cross-sectional area equals $0.57 \mathrm{M}^{0.68}$ ) and ectotherms (lizards and crocodilians; crosssectional area equals $0.11 \mathrm{M}^{0.76}$ ). Also plotted are three genera of Late Cretaceous dinosaurs (squares) and five genera of Permo-Triassic therapsids (diamonds; values for dinosaurs and therapsids were not included in regression calculations). 

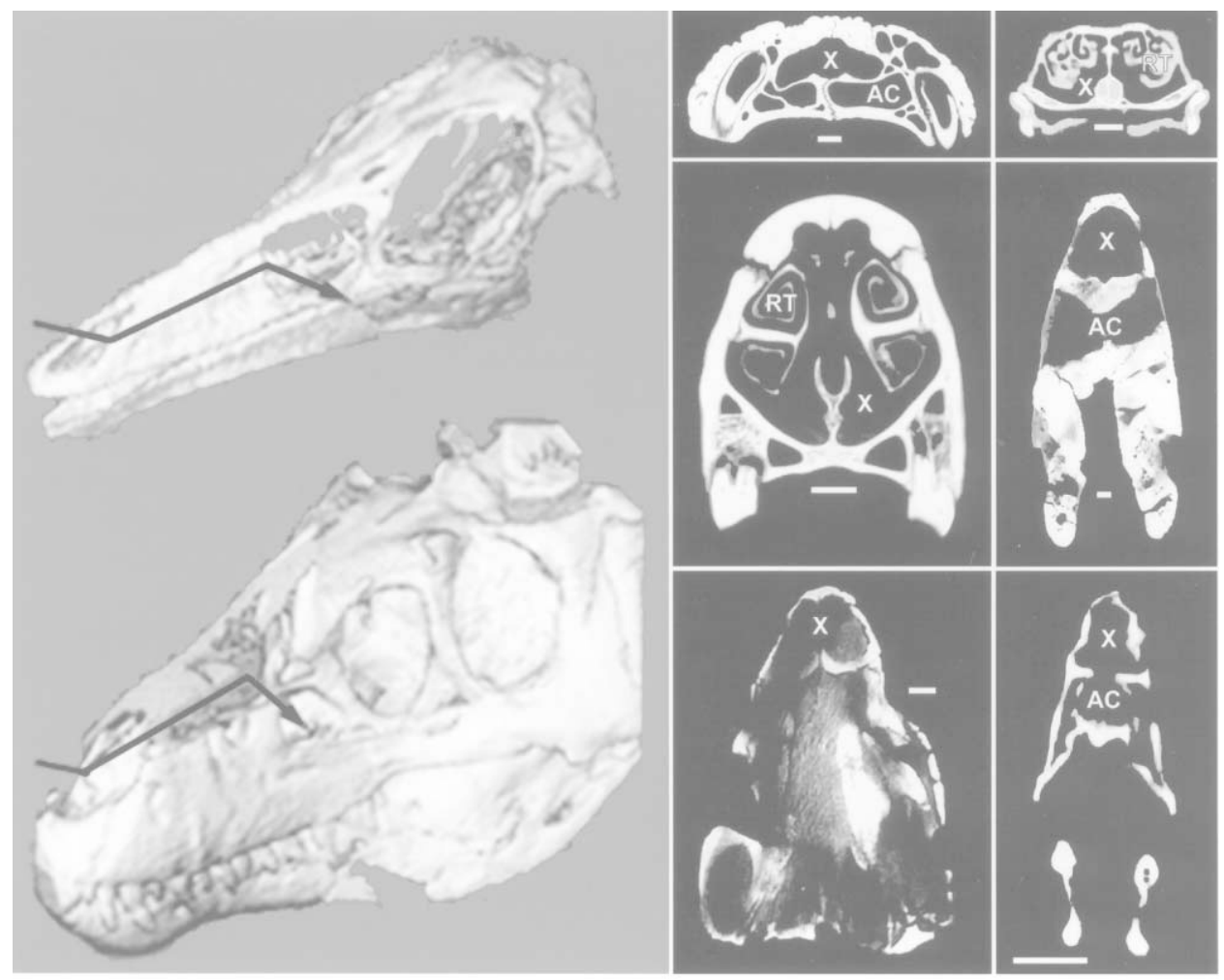

Figure 5. Left, Left lateral CT scans of the skulls of the theropod dinosaurs Ornithomimus (top) and Nanotyrannus (bottom). Arrows trace the path of airflow through the nasal passage. Right, Cross-sectional CT scans of the nasal passages in crocodile (upper left), ostrich (upper right), bighorn sheep (middle left), the theropods Nanotyrannus and Ornithomimus, respectively (middle and lower right), and the ornithischian dinosaur Hypacrosaurus (lower left). Respiratory turbinates are housed within voluminous nasal passages in birds and mammals. Like in living reptiles, relatively narrow nasal passages in dinosaurs are probably consistent with the absence of respiratory turbinates. Scale bar $=1 \mathrm{~cm} . A C=$ accessory (paranasal) sinus or cavity; $R T=$ respiratory turbinate; $X=$ midregion of the nasal passage.

possible to confidently infer nasal passage dimensions and, consequently, the presence or absence of respiratory turbinates in many less well-preserved specimens. In advanced theropods (tetanurans) and in archaeornithinine birds (e.g., Archaeopteryx, Confuciusornis), the maxillary and/or promaxillary fenestrae-apertures in the rostral portion of the antorbital fossa-always open into an expansive maxillary antrum and promaxillary sinus, respectively, and are not part of the nasal passage (Witmer 1997; Fig. 6). The ceilings of one or both of these sinuses form much of the floor of the nasal passage. Conversely, in modern birds, these sinuses have been pushed caudally, and their fenestrae are obliterated (Witmer 1997). This results, at least in part, from the expansion of the nasal passage to accommodate respiratory turbinates (Witmer 1997). Therefore, the occurrence of either of these fenestrae signals the likely presence of extensive paranasal sinuses that would have restricted the volume of the nasal passage in many theropods and in archaeornithine birds. Accordingly, it is highly unlikely that respiratory turbinates occurred in either the earliest birds or their theropod relatives.

Thus, in the avian lineage, the appearance of feathers and probably powered flight were likely to have preceded the development of endothermy. As in dinosaurs, the absence of respiratory turbinates in the earliest birds is inconsistent with their having attained an endothermic metabolic status. Significantly, other osteological features of ancient birds are also consistent with this scenario (e.g., the presence of annuli, or lines of seasonally arrested growth, in long bone sections; Chinsamy et al. 1994), and analysis of various attributes of the physiology and anatomy of extant birds also suggests that avian flight may have evolved before the origin of avian endothermy (Randolph 1994). This contrasts sharply with respiratory evolution in the therapsid-mammal lineage, where endothermic metabolic rates were likely to have developed before the appearance of the earliest mammal (Hillenius 1992; Ruben and Jones 2000).

Finally, we emphasize that reconstructing dinosaurs and early birds as ectothermic does not mean that these animals were necessarily vulnerable to temperature fluctuations, especially considering the mild climates of most of the Mesozoic Era (even particularly high-latitude, seasonally cooler regions may have been warmer and more equable than previously thought [Royer et al. 2002]). Although smaller forms ( $<75 \mathrm{~kg})$ may still have 

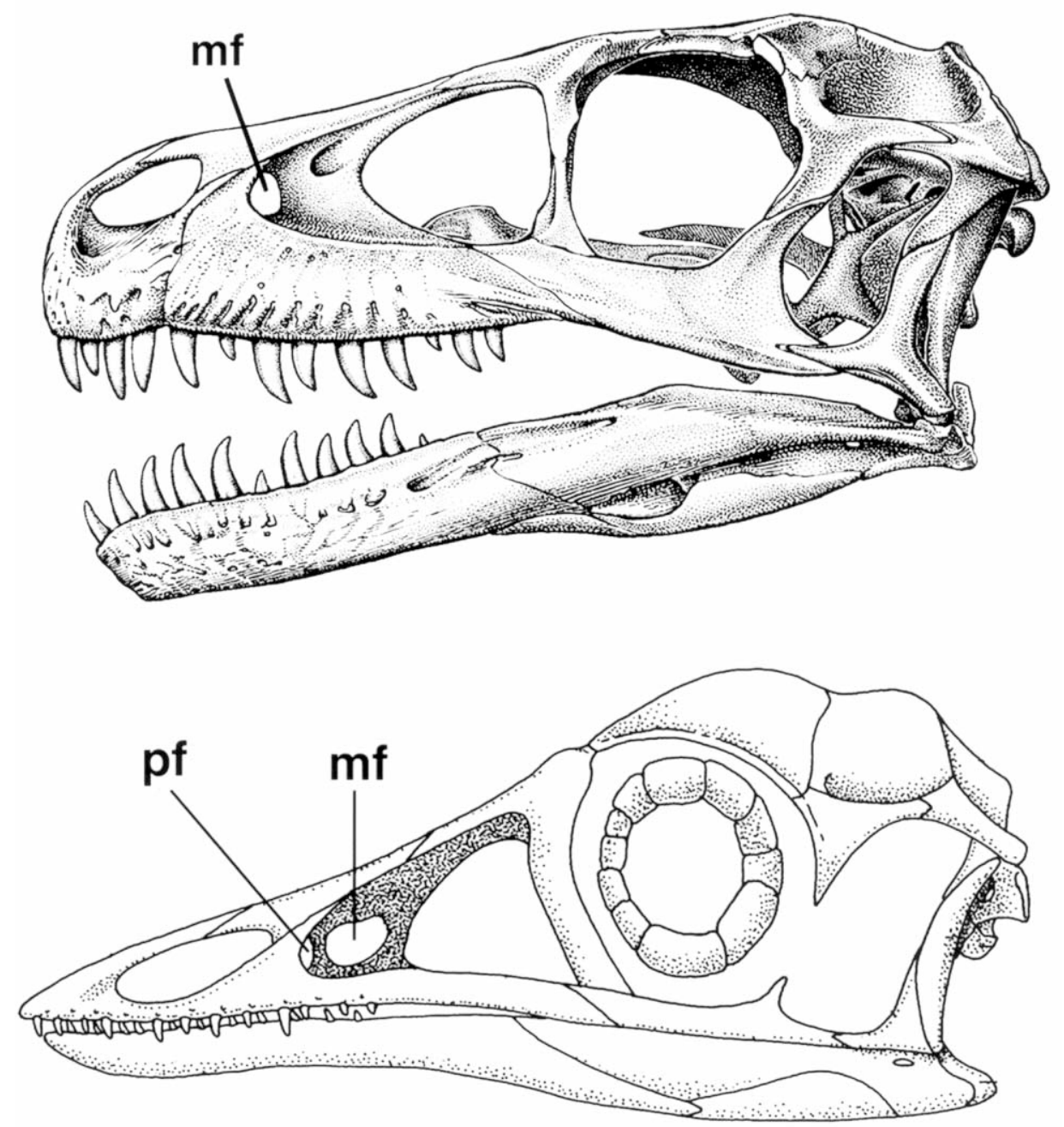

Figure 6. Promaxillary $(p f)$ and maxillary $(m f)$ fenestrae of the theropod dinosaur Dromaeosaurus (top) and the earliest known bird Archaeopteryx (bottom). Both fenestrae open into expansive paranasal sinuses, which are causally linked to narrow nasal passages and the likely absence of nasal respiratory turbinates. Modified from Currie (1997) and Chatterjee (1997), respectively.

been somewhat affected by diurnal temperature fluctuations, moderate-to-large forms $(>500 \mathrm{~kg}$ ) would be nearly unaffected by such changes (i.e., they would effectively have been homeothermic) and would respond only to fluctuations on a weekly to monthly scale. Moreover, given the metabolic capacities of many modern reptiles during burst-level activity, it is likely that early birds, even though ectothermic, were quite capable of uninterrupted powered flight for distances up to $1 \mathrm{~km}$ (Ruben 1991).

\section{Indicators of Activity Capacity}

Although evidence of the presence or absence of respiratory turbinates provides some insight into the resting or routine lung ventilation and metabolic rates in both extant and extinct taxa, these data do not necessarily serve as precise indicators of metabolic capacities of these animals during periods of exercise. However, paleontological and neontological evidence of lung morphology and ventilatory mechanisms in theropod dinosaurs and early birds facilitate hypotheses regarding their activity capacities.

\section{Lung Morphology and Ventilation in Extant Amniotes}

Amniote lungs are of two morphologically and ontogenetically distinct types, each of which is derivable from hypothetical ancestral simple saclike lungs. Extant theropsids (mammals) have alveolar lungs; extant sauropsids (i.e., chelonians, lepidosaurs, rhychocephalians, crocodilians, and birds) possess septate lungs (Ruben et al. 1997a).

Alveolar lungs are composed of millions of highly vascular- 
ized, spherical alveoli in which ventilatory airflow is bidirectional. During inhalation, expansion of the rib cage and/or contraction of the diaphragm increases pleural cavity volume, decreases pleural cavity pressure, and results in the expansion of the alveoli. Exhalation is accomplished, at least in part, by elastic rebound of the alveoli. The unique morphology of this lung, and especially of the alveoli, removes the necessity of high volumes of supporting parenchymal tissues and allows nearly all of the lung parenchyma to function actively in gas exchange (Perry 1983, 1989). These attributes, combined with a thin blood-gas barrier, provide the alveolar lung with a high anatomical diffusion factor (ADF; mass-specific ratio of vascularized pulmonary respiratory surface area to pulmonary bloodgas barrier thickness; Perry 1983, 1992; Duncker 1989), an attribute essential for maintenance of high rates of oxygen consumption during extended periods of intensive activity.

The general lung morphology of extant nonavian sauropsid amniotes (reptiles) is distinct from the alveolar lungs of mammals. The generalized sauropsid septate lung (a unicameral lung) is functionally analogous to a single, oversized mammalian alveolus. Septa-vascularized ingrowths-penetrate medially from the perimeter, forming respiratory units (i.e., trabeculae, ediculae, or faveoli depending on their depth), and are the principle sites of gas exchange (Perry 1983).

Variations from this generalized sauropsid septate lung morphology range from homogeneous to heterogeneous distribution of parenchyma, from one to many chambers, from dorsally attached to unattached, and from possessing no diverticulae to exhibiting many, elaborate diverticulae (Perry and Duncker 1980; Perry 1983). As in the mammalian lung, airflow in the reptilian septate lung during ventilation is bidirectional. However, unlike alveoli, the respiratory units of the reptilian septate lung contribute little to air convection during ventilation. Additionally, the amount of effective parenchymal tissue (parenchymal tissue volume/respiratory surface area), an indicator of the amount of nonrespiratory, supportive tissues, of the reptilian lung is significantly greater than that of the mammalian lung (Perry 1989). The result is a low relative overall ADF in reptiles (Perry 1983). To compensate, the ventral region of the lung in some nonavian sauropsids is often poorly vascularized and functions largely to assist in ventilation of dorsal, vascularized portions of the lung (Perry 1983). Although maximal oxygen consumption rates $\left(\dot{\mathrm{V}}_{2} \max \right)$ in some varanid lizards are significantly higher than those of other reptiles, no extant reptile is capable of achieving maximal aerobic respiratory exchange rates greater than about $15 \%-20 \%$ of those of typical endotherms (Hicks and Farmer 1998, 1999; Ruben et al. 1998). However, in a best-case scenario based on hypothetical improvements of the circulatory system and optimized pulmonary diffusion capacity, the reptilian septate lung might be capable of attaining about $50 \%-60 \%$ of these rates and thus might overlap with some of the less active mammals (Hicks and Farmer 1998, 1999; Ruben et al. 1998).
Birds, like all sauropsids, also possess septate lungs, but they have circumvented inherent constraints on respiratory gas exchange rates of the reptilian septate lung. Unlike reptiles, birds have a particularly high ADF. Additionally, modification of the nonvascularized chambers into a series of extensive, highly compliant air sacs that extend into the visceral cavity and aid in a specialized crosscurrent ventilation of the dorsal vascularized parabronchi during both inhalation and exhalation results in especially high rates of lung ventilation and gas exchange (Maina and Africa 2000).

The parabronchial lung in modern birds is securely attached to the vertebral column. In some birds, particularly those with notaria, there are distinct, inverted $\mathrm{T}$-shaped hypopophyses that serve as additional sites of attachment. Diverticulae from the air sacs invade and pneumatize portions of the skeleton. Pneumatization of the avian skeleton, with the exception of the long bones of the hindlimbs in a small subset of birds, is limited to the axial skeleton and forelimbs and results from invasion by the anterior (cervical and clavicular) air sacs but is not linked to respiratory function or specific lung morphology (Duncker 1989; McLelland 1989; Scheid and Piiper 1989).

Mechanisms for powering lung ventilation vary among extant amniotes. Lizards and snakes lack complete transverse subdivision of the body cavity (with partial separation, when present, resulting from the presence of an incomplete postpulmonary septum or, in some cases [e.g., macroteiids], by an incomplete posthepatic septum, but not both [Duncker 1989]) and rely primarily on costal ventilation, in which changes of pleuroperitoneal cavity pressure result from lateral expansion and contraction of the rib cage. To some extent, mammals and crocodilians also use rib cage movements to ventilate the lungs, but they also rely on diaphragm-assisted lung ventilation.

In mammals, the diaphragm consists of an airtight, transversely oriented, muscularized septum that completely subdivides the visceral cavity into anterior thoracic and posterior abdominal regions (Fig. 7). Muscular contraction of the diaphragm increases the volume of the pleural cavity, which reduces pleural cavity pressure, resulting in filling of the lungs.

In crocodilians, an airtight, transversely oriented diaphragm (composed of the postpulmonary and posthepatic septa [Goodrich 1930]) also completely subdivides the visceral cavity into anterior pleural-pericardial and posterior abdominal regions (Fig. 7). Unlike the mammalian diaphragm, the crocodilian diaphragm is nonmuscular and adheres to the anterior surface of the liver. The posterior and ventrolateral aspects of the liver serve as the insertion for the diaphragmatic muscles. These consist primarily of the large, ventral diaphragmaticus that takes origin primarily from the last pair of gastralia; a pair of thin lateral diaphragmatic muscles takes origin from the proximal shaft of the pubis and the small, preacetabular portion of the ischium (J. A. Ruben, T. D. Jones, N. R. Geist, personal observation; Fig. 8). Contraction of the diaphragmatic muscles 


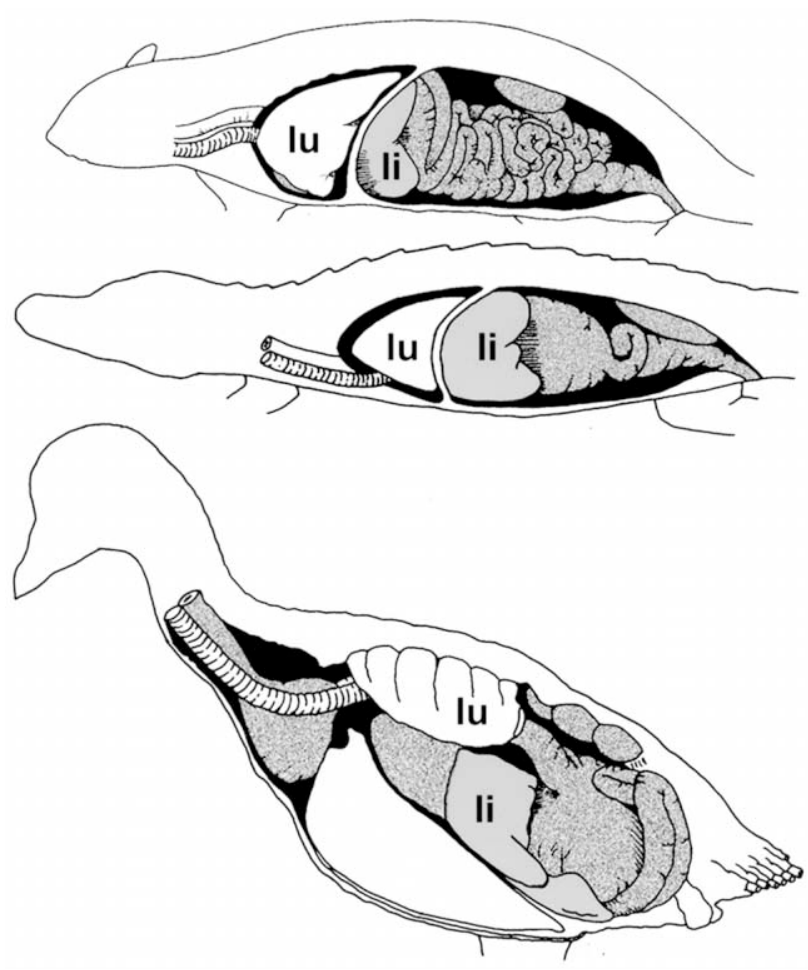

Figure 7. Body cavity partitioning correlates with lung ventilation mechanisms in extant amniotes. Only mammals (top) and crocodilians (middle) use active diaphragmatic lung ventilation. This necessitates a complete transverse fore-aft separation of the anterior, thoracic cavity from the abdominal cavity. Birds, which are exclusive rib breathers, exhibit no distinct anteroposterior separation of the body cavity (bottom). Abbreviations: $l i=$ liver; $l u=$ lung.

pulls the liver posteriorly in a piston-like manner, resulting in decreased pleural cavity pressure and filling of the lungs (Gans and Clark 1976).

The triradiate pelvis of extant crocodilians, with its stout, rodlike pubic rami, is ideally suited to provide support for the robust posterior gastralia, the primary site of origin for the large ventral portion of the diaphragmatic muscle (Figs. 8, 9). However, it is important to note that the elongate, distinctly theropod-like pubes of early (Triassic) crocodylomorphs (e.g., Terrestrisuchus [Crush 1984]) probably represent the pleisiomorphic pelvic morphology for this taxa (Fig. 9). Additionally, as in mammals, crocodilian lumbar ribs are reduced to allow lateral expansion of the viscera when the liver is pulled caudally during inhalation (Hengst 1998).

In most tetrapods, rectus abdominus musculature functions to support the abdominal viscera. However, in crocodilians, much of the rectus abdominus appears to have contributed to formation of diaphragmatic muscles (Carrier and Farmer $2000 a$ ). Consequently, in crocodilians, the gastralia, as well as passively aiding in lung ventilation by maintaining the volume of the body cavity, may aid the reduced rectus abdominus in its supportive role.

Birds, like lizards, lack a mammal- or crocodilian-like diaphragm and rely principally on costal-powered lung ventilation. Unlike reptilian ribs, those of birds possess unique intercostal and sternocostal joints that allow a sagittal rotation of the sternum and shoulder girdle. Significantly, the distal end of each sternal rib is expanded transversely and forms a robust hinge joint with the thickened anterolateral border of the sternum. These modifications facilitate ventilation of abdominal air sacs, while costal action results in a dorsoventral rocking motion of the posterior end of the enlarged sternum, which expands and contracts the air sacs (King 1966; Schmidt-Neilsen 1971; Brackenbury 1987; Fedde 1987). The highly derived avian lung air sac system, which permeates the entire pleuroperitoneal cavity, is dependent on the aforementioned skeletal features (Duncker 1972, 1974, 1989) and precludes the distinct transverse separation of avian body cavity that is typical of diaphragmbreathing tetrapods.

\section{Lung Morphology and Ventilation in Early Birds and Dinosaurs}

Given their relationship to living reptiles and birds, extinct sauropsids_-including dinosaurs_-probably possessed septate lungs. However, they were unlikely to have possessed avianstyle, flow-through lungs. The rib cage-pectoral girdle complex of these forms lacks indications of avian-like thoracic musculoskeletal capacity for inhalatory filling of abdominal air sacs. Ossified sternal ribs are documented for the sauropod Apatosaurus (Marsh 1883; McIntosh 1990) and several derived theropods, including oviraptorids (e.g., Clark et al. 1999), ornithomimids (e.g., Pelecanimimus; J. A. Ruben, T. D. Jones, N. R. Geist, personal observation), and dromaeosaurids (e.g., Ostrom 1969; Norell and Makovicky 1999), but in each case the sternal ribs lack the morphology of the avian sternocostal joints. Importantly, mere costosternal articulations alone cannot be considered diagnostic for any particular lung morphology or ventilatory mechanism: such articulations between ribs and sternae occur in most amniotes, including lepidosaurs, crocodilians, and mammals (e.g., Goodrich 1930; Romer 1956). The sternal plates are known from a variety of dinosaur taxa (e.g., ankylosaurs [Coombs and Maryanska 1990], ornithopods [Norman 1980; Coombs and Maryanska 1990; Forster 1990], ceratopsians [Sereno and Chao 1988], and sauropodomorphs [Young 1947; McIntosh 1990] as well as oviraptorids [Barsbold 1983; Clark et al. 1999], ornithomimids [Perez-Moreno et al. 1994], and dromaeosaurids [Barsbold 1983; Norell and Makovicky 1997; Xu et al. 1999; Burnham et al. 2000; Maryanska et al. 2002]) but are relatively short and in all cases lack the thickened lateral border and the transversely oriented articulations for the sternal ribs that characterize the sterna of all extant birds. The sternal plates of the immature dromaeosaur 


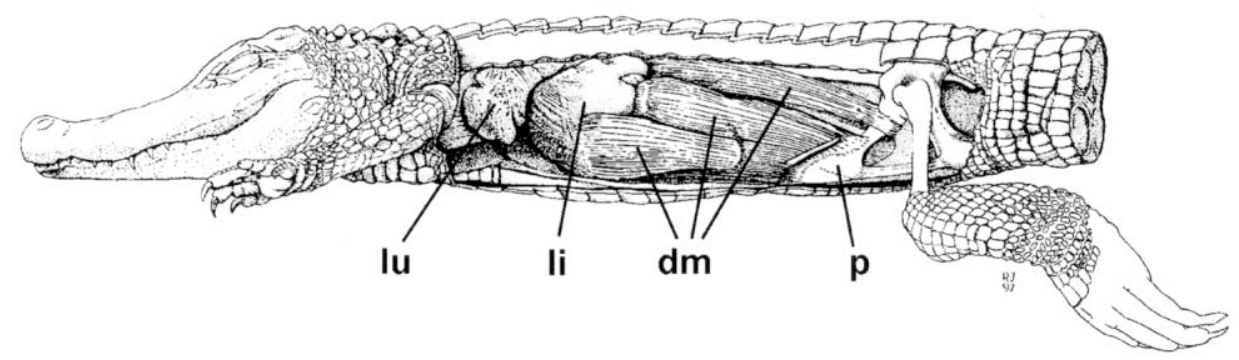

Figure 8. Hepatic piston-lung ventilatory mechanism of crocodilians. Extensive ventral diaphragmatic muscles take origin primarily from the last pair of gastralia. More delicate lateral diaphragmatic muscles originate from the preacetabular processes of the ischium and the shafts of the pubes. Abbreviations: $d m=$ diaphragmatic muscles; $l i=$ liver; $l u=$ lung; $p=$ pubis. Illustration by R. Jones; modified from Ruben et al. $(1997 a)$.

Bambiraptor are relatively long, but its lateral edges, including the regions where the sternal ribs articulated, are thin (Burnham et al. 2000).

The presence of avian-like uncinate processes, posterodorsal projections on the thoracic ribs, in oviraptorids (Clark et al. 1999) and some dromaeosaurids (Norell and Makovicky 1999) is sometimes mentioned in this context (e.g., Paul 2001; Perry 2001). However, avian uncinate processes appear to function primarily in strengthening the rib cage and stabilizing the shoulder musculature (Bellairs and Jenkin 1960; King and King 1979; Hildebrand and Goslow 2001); they have no particular role in sternocostal ventilation of the avian lungs. Uncinate processes are absent in screamers (Anseriformes: Anhimidae) and may be reduced in other birds (Bellairs and Jenkin 1960; Brooke and Birkhead 1991). Furthermore, cartilaginous or ossified uncinate processes are also known from crocodilians (Hofstetter and Gasc 1969; Duncker 1978; Frey 1988), Sphenodon (Wettstein 1931; Hofstetter and Gasc 1969), and even several labyrinthodont amphibians, such as Eryops (Gregory 1951). Thus, the presence of uncinate processes does not necessarily signal any particular suite of respiratory adaptations.

Similarly, the pneumatized vertebrae of sauropods and some theropods, which resemble those of extant birds, have been cited as evidence of a birdlike lung air sac system (Bakker 1986; Reid 1997; Britt et al. 1998; Perry and Reuter 1999; Perry 2001). However, in modern birds, pneumatization of the vertebrae and ribs is invariably accomplished by diverticuli of the cervical air sacs (McLelland 1989), which are located outside the trunk and contribute little if anything to the respiratory air flow (Scheid and Piiper 1989). Presence of pneumatized vertebrae in dinosaurs therefore signifies the possible presence of nonrespiratory diverticuli but cannot be regarded as indicative of an extensive, avian-style air sac system.

Consequently, there is no compelling evidence that any dinosaur possessed thoracic skeletomuscular modifications to ventilate a birdlike lung air sac system. It is possible that a less highly derived, "proto-air-sac" lung may have existed in some dinosaurs (Perry 1992, 2001), but at present, there is no in- dication of the presence thereof, and such a reconstruction must be considered speculative (Perry and Reuter 1999).

It has been suggested that theropod dinosaurs might have mobilized their well-developed gastralia, or "belly ribs," to have generated negative abdominal pressure during inhalation, thereby facilitating expansion of posterior, birdlike air sacs (Carrier and Farmer 2000a; Farmer and Carrier 2000a). We view this scenario with skepticism for a variety of reasons: (1) crocodilians and rhynchocephalians possess well-developed gastralia, but these perform no known role in active generation of either negative or positive abdominal pressure during lung ventilation; (2) in extant crocodilians (and other living reptiles), neither of the muscles hypothesized to have caused active ex-

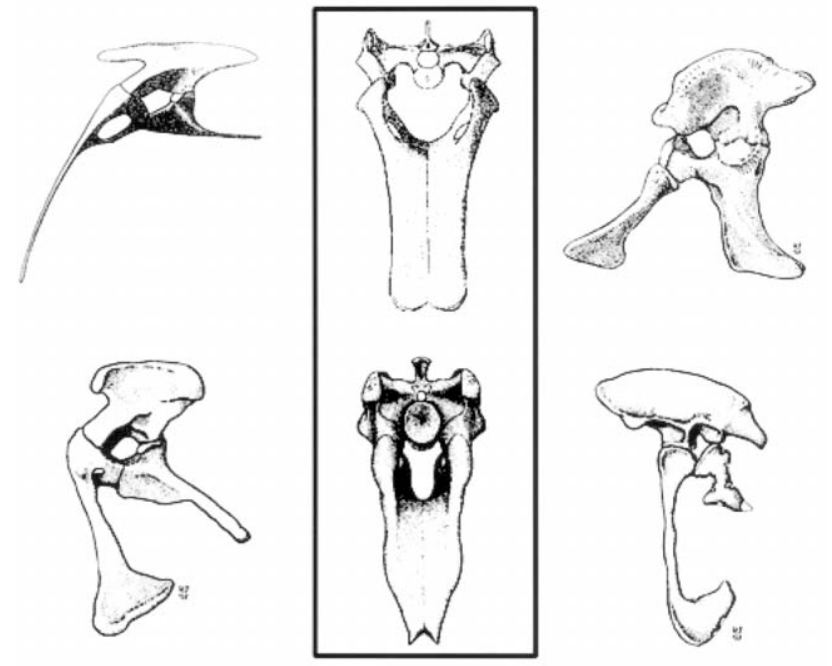

Figure 9. Left lateral and anterior views of the pelves of crocodylomorphs and theropod dinosaurs. Crocodylomorphs Terrestrisuchus (upper left, upper center) and Alligator (upper right); theropods Herrerasaurus (lower left, lower center) and Unenlagia (lower right). Note the marked similarity between theropod and crocodilian pubes. Modified from Ruben et al. (1997a), Crush (1984), and Novas (1993). Illustrations for Alligator, Herrerasaurus, and Unenlagia by R. Jones. 
pansion of theropod gastralia (i.e., ischiopubis and/or ischiotruncus muscles) insert on sites appropriate to have generated such movements (via posterior rotation of medial gastralia elements); (3) gastralia are restricted to the ventral abdominal wall, and theropods possessed deep, laterally open, lumbar flank regions. Consequently, inefficient, paradoxical medial movements of the lateral abdominal wall would likely have been unavoidable during the postulated gastralia-powered, negative abdominal pressure cycles requisite for expansion of posterior air sacs.

The Early Cretaceous compsognathid Sinosauropteryx (Chen et al. 1998) retains, along with ocular and integumentary tissues, preserved traces of much of the contents of the visceral cavity. The cavity exhibits complete thoracic-abdominal separation, delimited by a transversely oriented subdivision coincident with the anterior surface of the liver (Fig. 10). Additionally, theropods possessed reduced posterior dorsal (lumbar) ribs, well-developed gastralia, and a triradiate pelvis similar to that in crocodilians (Fig. 9). These are consistent with the hypothesis that theropod dinosaurs, like modern crocodiles (and, especially, early crocodilians), probably possessed a bellows-like septate lung and that the lung was ventilated, at least in part, by a hepatic piston-diaphragm powered by diaphragmatic muscles that extended between the pubes and liver. Significantly, fossilized preservation of abdominal contents whose general arrangement is consistent with diaphragm breathing is not unique to Sinosauropteryx. Similar transverse segregation of the viscera is seen in an undoubted diaphragm breather, Pholidocercus, a mammal from the Eocene Messel formation of Germany (von Koenigswald et al. 1988; Fig. 10).

Recently, a juvenile maniraptoran theropod dinosaur with exquisitely preserved soft tissue was described. As well as having a remarkably preserved skeleton, Scipionyx samniticus retains fossilized skeletal muscles, trachea, large intestines, and liver in situ (Dal Sasso and Signore 1998a, 1998b; Ruben et al. 1999). A section of the trachea is preserved in the posterior cervical region, immediately anterior to the scapulocoracoid complex (Dal Sasso and Signore 1998a). Like the trachea of crocodilians, Scipionyx's trachea in this region is situated well ventral to the vertebral column. In contrast, the avian posterior cervical trachea, except in specialized, long-necked birds (e.g., swans), is usually positioned dorsally and adjacent to the vertebral column, thereby facilitating entry of the trachea into the dorsally attached parabronchi (McLelland 1989).

In visible light, the liver of Scipionyx appears as a small hematitic halo restricted to the ventral margin of the anterior portion of the visceral cavity (Dal Sasso and Signore 1998a, 1998b). However, the liver is more accurately visualized under

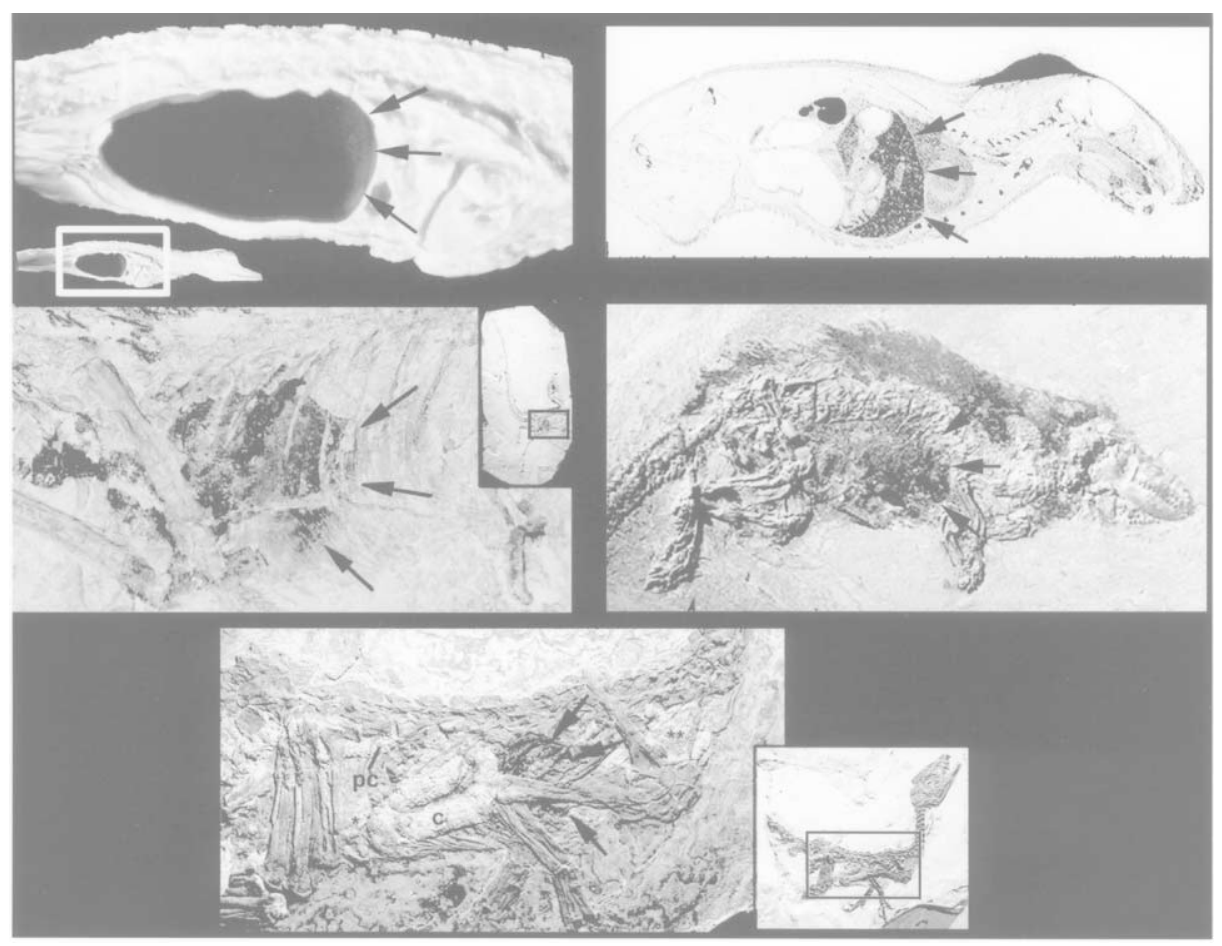

Figure 10. Similar, fore-aft body cavity partitioning in Alligator (top left), the theropod dinosaurs Sinosauropteryx (middle left) and Scipionyx (bottom), and the rat and the Eocene mammal Pholidocercus (modified from von Koenigswald et al. 1988). In each case, arrows delineate the complete vertical separation of the anterior, thoracic, and posterior abdominal cavities from one another. Insets show entire specimen. See also Figure 7. Abbreviations: $c=$ colon; $p c=$ posterior colon. 
ultraviolet illumination, where it fluoresces as a suboval, indigocolored mass that extends from the vertebral column to the ventral body wall (Ruben et al. 1999; Fig. 10). As in extant diaphragm breathers, Scipionyx's liver is situated ahead of the large intestine and fills the anteriormost portion of the abdominal cavity (Ruben et al. 1999). Furthermore, as in crocodilians, mammals, and the theropod Sinosauropteryx, the anterior border of the liver in Scipionyx is transversely oriented and completely subdivides the visceral cavity into anterior pleuropericardial and posterior abdominal regions (Ruben et al. 1999). In the theropods Scipionyx and Sinosauropteryx and the mammal Pholidocercus, the pleural cavity appears empty because delicate lung tissues were not fossilized (Fig. 10).

Suggestions that the obvious fore-aft subdivision of the visceral cavities in Sinosauropteryx and Scipionyx are merely the result of fortuitous "cracks" or postmortem organ displacement (Paul 2001) strain credulity. Cracks that do exist in the Sinosauropteryx fossil clearly do not coincide with diagnostic portions of the preserved abdominal remains (Chinsamy and Hillenius, in press; J. A. Ruben, T. D. Jones, N. R. Geist, personal observation). With regard to Scipionyx, there is little question that the skeleton, various muscles, and intestines have been preserved in situ, and we see no logical reason to assume that the structure and placement of the liver is not as it was in life.

Portions of the large intestine and trachea of Scipionyx are visible and also appear to have been preserved in situ (Dal Sasso and Signore 1998a, 1998b; Ruben et al. 1999). Notably, the posterior colon, or colorectal intestine, is situated far dorsally, at about the same level as the vertebrae in the lumbarsacral region. This condition is comparable to the position of the colon in living taxa such as crocodilians and mammals (Fig. 11; Ruben et al. 1999). In contrast, the colon (or rectum) of birds is invariably suspended by the dorsal mesentery (mesocolon) so that it is situated in the midabdominal cavity, some distance from the roof of the cavity (Fig. 11; Duncker 1989). This midabdominal suspension of avian large (and small) intestines is necessary to accommodate the dorsally and medially attached abdominal air sacs (which extend caudally from the dorsally attached parabronchi).

A report of an incomplete theropod fossil (Martill et al. 2000) that includes a short section of colorectum with a supposedly birdlike, midabdominal location should be regarded with skepticism. The element in question courses posterodorsally toward the pubic canal at a sharply oblique angle (ca. $45^{\circ}$ ) to the vertebral column; it then abruptly flexes ventrally as it passes through the puboischiac canal approximately parallel to the vertebral column. We are aware of no extant bird or crocodilian that exhibits colonic anatomy wherein the posterior, colorectal region is thrown into similarly sharp flexures that would almost certainly obstruct smooth movement of fecal matter toward the cloaca. Significantly, the avian colorectum is almost invariably a straight tube that extends through the midabdominal cavity in a course parallel to the vertebral column. Compared
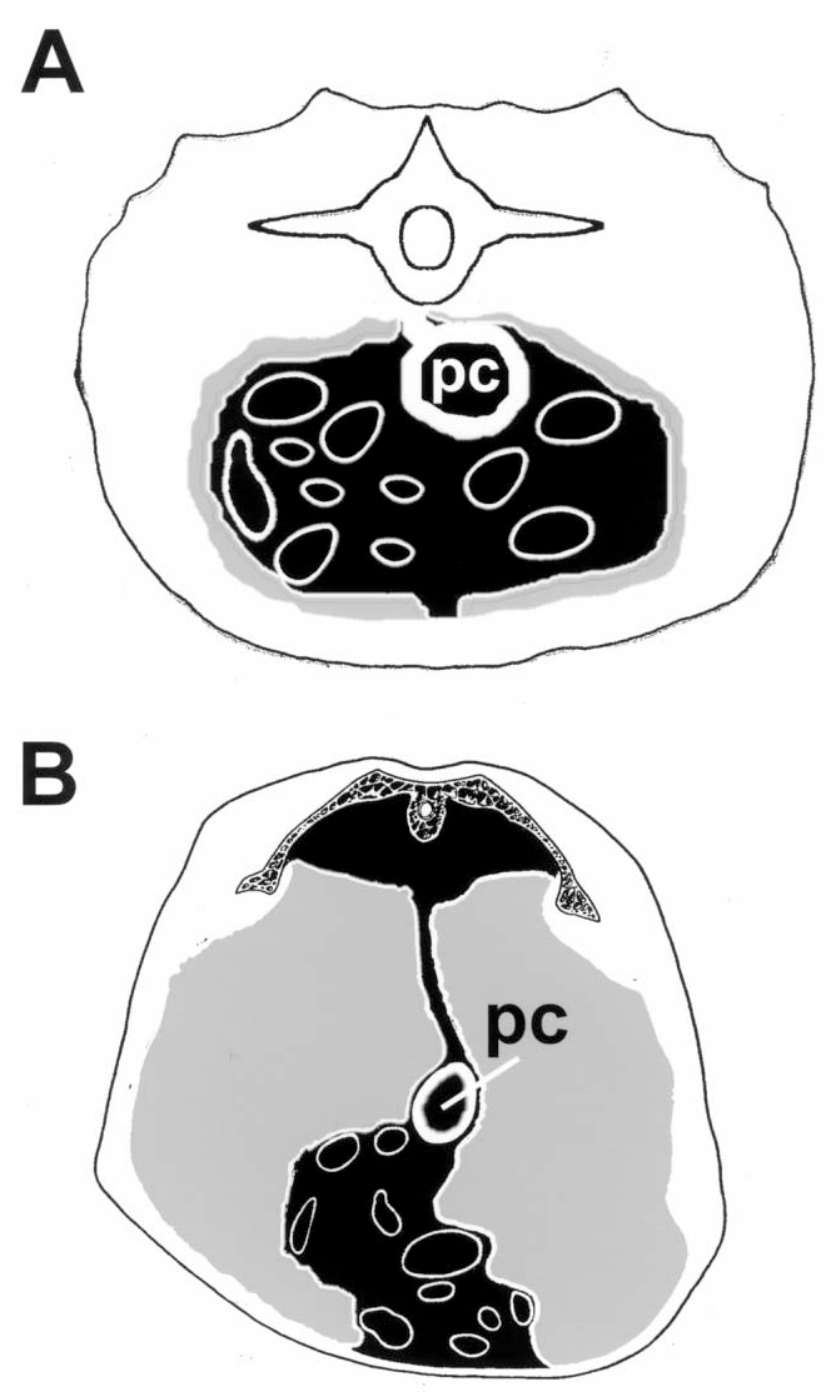

Figure 11. Relation of the posterior colon $(p c)$ to the roof of the abdominal cavity in $(A)$ crocodilians and $(B)$ birds. Areas in gray represent the coelomic cavity. Unlike crocodilians and the theropod Scipionyx, the posterior colon of birds is situated ventrally, some distance from the roof of the visceral cavity, in order to accommodate abdominal air sacs. After Duncker (1989).

with extant archosaurians, the location of the colorectum in this specimen almost certainly reflects postmortem ventral displacement of soft tissues.

Accordingly, it is unlikely that avian-style, abdominal air sacs were present in Scipionyx or Sinosauropteryx and, by extension, in other theropod dinosaurs. Since abdominal air sacs are of fundamental importance to the function of the lung in extant birds (Duncker 1971), their likely absence is another indication that an avian-style, flow-through, air sac lung was absent in theropod dinosaurs. Alternately, Scipionyx's axial skeletal features and distinct visceral organization are consistent with the presence of hepatic piston, diaphragm-breathing. 
Objections to the hepatic-piston model fall principally into two categories: (1) that there was insufficient space on the theropod pubis to have accommodated diaphragmaticus musculature and (2) that theropods were unlikely to have been diaphragm ventilators because their pelvis, with its fixed pubes, differed from the mobile pubes of living crocodilians. These criticisms are poorly supported by both theropod and crocodilian anatomy and ventilatory physiology in crocodilians. Hutchinson (2001) considers it unlikely that theropods had a crocodilian-like diaphragmaticus muscle because puboischiofemoralis muscles supposedly occupied the anteroposterior surfaces of the fused pubic rami, or pubic apron. However, in crocodilians, the pubic rami are not major sites of origin for the diaphragmaticus musculature. Instead, the large, ventral portion of the diaphragmaticus attaches primarily to the last pair of gastralia; some slips of this muscle may originate directly from the pubis, but these attach to the craniolateral edge of the distal part of the pubis, ventrally adjacent to the sites of attachment of the puboischiofemoralis muscles (other slips of the diaphragmaticus insert more proximally on the pubis and the preacetabular region of the ischium [Ruben et al. 1997a]; Carrier and Farmer 2000a, 2000b; Farmer and Carrier 2000a). Elsewhere, Hutchinson (2001) asserts that the lateral surface of the distal pubis and the pubic boot of theropods served mainly for abdominal muscles, including the rectus abdominus, thereby leaving no room for insertion of the diaphragmaticus. However, insofar as the crocodilian diaphragmaticus muscles are likely derivatives of the rectus abdominus (Carrier and Farmer 2000a), there would seem to be little, if any, conflict between Hutchinson's (2001) reconstruction of theropod pelvic musculature and the presence of a diaphragmaticus muscular system in these animals. Interestingly, the pubis of some theropods exhibits marked posterior retroversion (e.g., in Herrerasaurus and some dromaeosaurid theropods). In such cases, the result might have been enhanced lung tidal volume as a consequence of elongation of the diaphragmaticus muscle and additional posterior "travel" of the liver during hepatic piston ventilation.

In another instance, the mobile pubes of modern crocodilians were asserted to be essential for operation of a hepatic piston diaphragm (Carrier and Farmer 2000a, 2000b; Farmer and Carrier 2000a, 2000b). Supposedly, avoidance of greatly elevated intra-abdominal pressure otherwise associated with posterior movement of the liver during inhalation is made possible only by concomitant, backward rotation of the pubes. However, experimental data broadly falsify these assertions: alligators with surgically fixed pubes exhibit no alteration in intraabdominal pressures during exercise-induced periods of enhanced lung ventilation (Harwell et al. 2002). Instead, posterior, inhalatory rotation of the liver and lung tidal volume are reduced by about $15 \%$ in these animals. It is likely that the mobile pubis of alligators serves to enhance tidal volume (via supplemental, backward movement of the liver during inhalation) and is probably a secondary specialization to compensate for reduced tidal volume capacity in aquatic, dorsoventrally flattened crocodilians. As noted above, early crocodylomorphs (e.g., Terrestrisuchus) were terrestrial, not aquatic, and exhibited deeper bodies and pelvic anatomy markedly like that of theropods rather than that of modern crocodilians (Frey 1988).

Interestingly, hepatic-piston diaphragm breathing may have been a primitive (plesiomorphic) attribute for the archosaurs. In addition to crocodilians and theropod dinosaurs, pterosaurs were almost surely diaphragm breathers as well; in many advanced pterosaurs, the presence of a virtually immovable, fixed rib cage as well as a crocodile-like pubis and well-developed set of gastralia are fully consistent with diaphragm breathing (Carrier and Farmer 2000a; Jones and Ruben 2001).

Like their dinosaurian relatives, Archaeopteryx and early birds also lacked the thoracic skeletal modifications consistent with the ability to have ventilated an avian-style lung. However, as in modern arboreal birds, we interpret the pubis in early birds to have been nearly horizontal and, more importantly, to have extended well posterior to the ilium and ischium (based on the arrangement of the best preserved examples of Archaeopteryx, i.e., the Berlin and Solnhofen specimens and known enantiornithine birds; Martin 1991; J. A. Ruben, personal observation; Fig. 12). Importantly, Archaeopteryx and some early birds (e.g., Confuciusornis) apparently possessed laterally expanded, dorsally concave hypopubic cups at the distal end of their pubes (Fig. 13; Ruben et al. 1997a; Jones and Ruben 2001). The similarity of the pubic morphology of modern and early birds indicates that this hypopubic cup may have served as the site of origin for suprapubic musculature and is inconsistent with hepatic piston-diaphragmatic lung ventilation. Consequently, it is reasonable to conclude that when roosting in trees, early birds probably also utilized suprapubic and infrapubic musculature to assist in ventilation of incipient nonvascularized posterior air sacs (Fig. 12).

Unlike most early birds, Archaeopteryx has been interpreted as adapted for a terrestrial rather than an arboreal existence (Ostrom 1991; Peters and Görgner 1992). The severely opisthopubic pelvis and the presence of the hypopubic cup of Archaeopteryx, as in enantiornithines, signal that early birds, including Archaeopteryx, were probably adapted for a substantially arboreal existence. Hence, the pelvis of Archaeopteryx and other early birds may evince the likely long arboreal history of their ancestry.

\section{Reproductive Biology}

Evidence for ectothermic metabolic physiology in dinosaurs and early birds also provides new insight into previously studied aspects of reproduction in these taxa. 

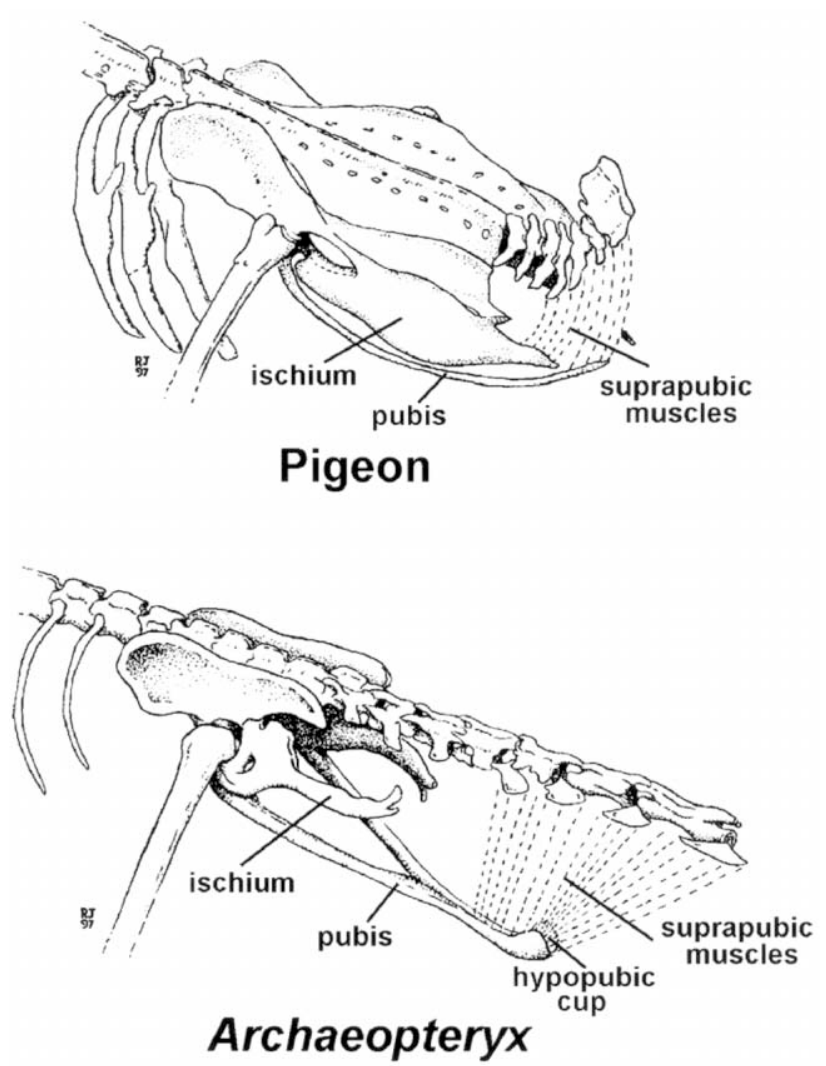

Figure 12. Pelvic and tail skeleton and suprapubic musculature of modern perching birds (e.g., pigeon) and Archaeopteryx. In both extant and extinct arboreal birds, marked projection of the distal pubis posterior to the ilium and ischium is, and probably was, associated with suprapubic musculature rotation of the pelvis and tail. Such movements facilitate ventilation of the nonvascularized air sacs during arboreal roosting. This condition of the pubis is broadly inconsistent with the morphology of the theropod pelvis and with hepatic-piston diaphragmatic breathing. Anterior is to the left of the figures. Illustration by R. Jones.

\section{Incubation}

All amniotes incubate (apply heat to) their eggs and/or young either through endothermic means (i.e., by brooding, the application of body heat) or ectothermic means (using environmental heat sources). Birds and oviparous reptiles display a wide range of incubation behaviors. However, although many may closely guard their nests (Cott 1961, 1971; Martoff et al. 1980; Shine 1988; Coombs 1989; Lang 1989; Gans 1996; Geist and Jones 1996; Pough et al. 1998), extant reptiles are not known to directly manipulate their nests or eggs to control the temperature. Living birds almost universally incubate their eggs by brooding (Welty and Baptista 1988; Gill 1994). Consequently, extant birds are likely to disturb eggs when they come in contact with them during brooding and, in any case, birds must constantly turn and redistribute their eggs in the nest to ensure equal temperature distribution (Drent 1972). This egg turning prevents premature adhesion of the chorioallantois to the inner shell membranes, which would disrupt the albumen uptake by the embryo and prevent the embryo from assuming the tucking position essential for hatching (Drent 1972; Gill 1994). In sharp contrast, egg manipulation and/or rotation are usually fatal for the eggs of crocodilians and other reptiles (Grenard 1991).

In this regard, it is unlikely that any dinosaur brooded its eggs in a birdlike manner. All known in situ dinosaur clutches (including those from both saurischians and ornithischians) contain at least partially buried eggs whose placement within the nest indicates that postdepositional manipulation was unlikely (Seymour 1979; Horner 2000). For example, the symmetrically paired arrangement of all known troodontid and oviraptorid theropod eggs, coupled with the fact that these eggs are always at least partially buried in sand (Varricchio et al. 1997; Dong and Currie 1998), is inconsistent with postdepositional manipulation. Moreover, partial or complete burial of eggs would have resulted in, at best, an inefficient transfer of maternal body heat to eggs (Varricchio et al. 1997).

Nevertheless, finds of adult Oviraptor (Norell et al. 1995; Dong and Currie 1998) and Troodon (Varricchio et al. 1997) in apparent contact with egg clutches have been interpreted as demonstrating birdlike brooding (i.e., application of body heat to eggs or young) behavior. Norell $(1995$, p. 60$)$ states that the incubation behavior of birds "is implicitly tied to the warmblooded metabolism of living birds" and implies that the presence of such behavior in Oviraptor indicates endothermy in these dinosaurs. Although Norell et al. (1995) admit that apparent brooding-like behavior and endothermy are not necessarily correlated, they nevertheless conclude that modern avian brooding behavior was present in maniraptoran theropods. However, close proximity and even physical contact of parent and nests occur widely among reptiles, including turtles, squamates, and crocodilians (Gans 1996; Shine 1988; Pough et al. 1998). Female crocodilians often lie on top of the nest during nest guarding (Coombs 1989; Lang 1989), and it has been reported that they will rest their lower throat or thorax directly on the nest during the incubation period (Cott 1961, 1971). Consequently, the position of the oviraptorid on the nest does not necessarily signal avian-style brooding. Rather, reptile-like nest or egg attendance adequately explains these fossils. Finally, it has been argued that the "folded-under" posture of the limbs of these dinosaurs is much more avian than crocodilian (Norell and Clark 1996). However, this is probably a function not of the avian-like nature of dinosaurs but of the relative lengths of the limbs. Given the relatively short limbs of modern crocodilians, it is absurd to expect them to take on an avian pose on the nest. Similarly, there is no compelling reason to assume that the folded limbs of dinosaurs necessarily denote avian incubation behavior.

Interestingly, given the probable ectothermic status of $\mathrm{Ar}$ - 


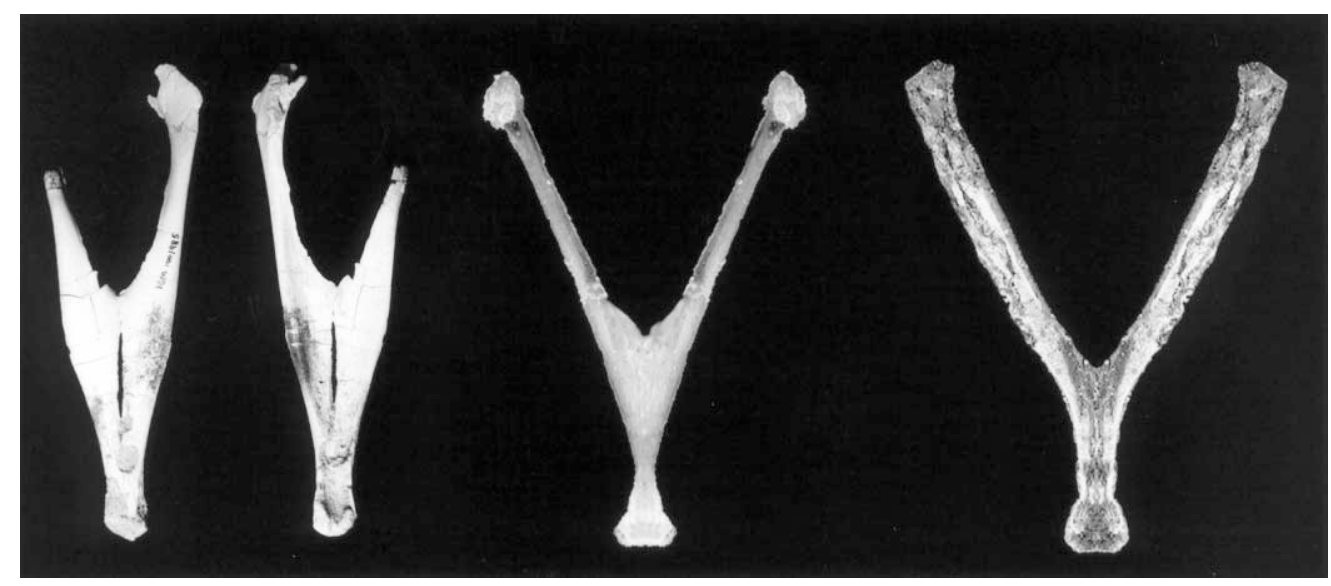

Figure 13. Pubes of theropods and birds. Left, Anterior and posterior view of the pubes of Velociraptor (modified from Norell and Makovicky 1997). Center, Posterodorsal view of the pubes of Archaeopteryx (reconstructed from the right pubis of the London specimen) and Confuciusornis (right; reconstructed from the right pubis of IVPP V 11552). Only the pubes of early birds (e.g., Archaeopteryx and Confuciusornis) possess a convex, laterally expanded hypopubic cup at their distal ends.

chaeopteryx and other early birds, it is reasonable to expect that their incubation habits, like those of dinosaurs, were more similar to those of living "reptiles" than to those of extant birds. True avian brooding (e.g., egg turning and incubation by application of body heat) likely resulted only after the advent of endothermy and therefore may be unique to ornithurine birds.

\section{Hatchling Maturity}

On the basis of long bone developmental histology, Horner et al. (2001b) argue that the supposedly high proportion of calcified cartilage to endochondral bone in some dinosaurs is indicative of hatchling altriciality at eclosion. This is problematic on several levels. Their assertion that "some dinosaur neonates passed through a stage where the entire metaphyses were calcified, but not ossified" (Horner et al. 2001a, p. 51) is contrary to any known patterns of long bone development in extant reptiles and birds. In fact, significant amounts of calcified cartilage are known only from large, mature individuals of one vertebrate taxon-Chondrichthyes (cartilaginous fish). Moreover, calcification of the growth zone would impair growth.

Furthermore, Horner et al. (2001a) seem also to present data inconsistent with their own conclusions. The absolute and relative thickness of the "calcified hypertrophic cartilage" (CHC) in the "epiphyses" (i.e., $\mathrm{CHC}$ thickness and the ratio of $\mathrm{CHC}$ thickness to overall element length, respectively) of presumably altricial hadrosaurs ( $\mathrm{CHC}, 12-19 \mathrm{~mm}$; relative $\mathrm{CHC}, 2.89-6.83$ ) overlap those of extant, precocial birds (CHC, 8-25 mm; relative $\mathrm{CHC}, 3.2-7.5)$. Finally, there is no evidence that the proportion of endochondral bone in the epiphyses of extant birds or reptiles is indicative of maturity. To the contrary, it has been demonstrated that it is not possible to separate altricial, semialtricial, semiprecocial, and precocial hatchlings according to the degree or pattern of ossification of their skeletons (Starck 1996). Additionally, since the distal portion of the "CHC" is not preserved (Horner et al. 2001a), there is no way to accurately measure its thickness. The evidence presented by Horner et al. (2001a) notwithstanding, we agree with Norell and Clark (1996, p. 165) that precocity in dinosaur young is "expected because both crocodiles and ratite birds [the basal sister group to all other living birds] are precocial at hatching." The interpretation of the presence of dinosaur altriciality and large calcified cartilaginous masses in the long bones of dinosaur perinates should be regarded with skepticism (J. M. Starck, personal communication).

\section{Summary}

Utilization of comparative physiology and anatomy has provided exciting new insight into the biology of many long-extinct taxa. Surprisingly, solid inferential evidence-for example, the absence of respiratory turbinates-indicates that dinosaurs and early birds were likely to have maintained ectotherm or ectotherm-like resting, or routine, metabolic and lung ventilation rates. Nevertheless, some may have possessed the capacity for sustained activity that might have approached that in some endotherms.

As in extant reptiles, costal breathing was likely to have supported active rates of oxygen consumption in such animals. Consequently, based on the physiology of most extant ectotherms, a specialized diaphragm to supplement ventilation in theropod dinosaurs seems superfluous. However, a variety of data suggest that expansion of lung ventilatory capacity might have allowed multicameral, septate lungs in dinosaurs to have achieved rates of $\mathrm{O}_{2}-\mathrm{CO}_{2}$ exchange that might have approached those of a few mammals with relatively low aerobic scopes 
(Hicks and Farmer 1998; Ruben et al. 1998). Thus, the presence of diaphragm-assisted lung ventilation in theropods might indicate that, although these dinosaurs maintained ectothermlike routine metabolic rates, they were, nevertheless, uniquely capable of sustaining active oxygen consumption rates and activity levels beyond those of the most active living reptiles.

This hypothesized pattern of metabolic physiology in theropods may seem inconsistent with the presence of a hepatic piston diaphragm in extant crocodilians, none of which appears to have particularly enhanced capacity for oxygen consumption during exercise (Bennett et al. 1985). However, relatively low aerobic capacity in recent crocodilians, all of which are secondarily aquatic, might not represent the ancestral condition. Because early (Triassic) crocodylomorphs (e.g., Protosuchus and Terrestrisuchus) appear to have been fully terrestrial, cursorial, and relatively active (Colbert and Mook 1951; Crush 1984), they, like theropods, might also have had enhanced aerobic capacities.

Such a scenario may have afforded theropods, early crocodylomorphs, and, perhaps, pterosaurs the low maintenance cost of ectothermy combined with enhanced endurance similar to that in some modern endotherms. This strategy might have functioned optimally in the relatively mild, equable climatic regimes of most of the Mesozoic Era, where chronic maintenance of ectothermic homeothermy would have been possible (as in the Varanus komodoensis [McNab and Auffenberg 1976; Spotila et al. 1991]).

Relatively little is known about many aspects of reproduction in dinosaurs and early birds. Nevertheless, their likely ectothermic metabolic status as well as evidence from many dinosaur egg and perinate fossils is consistent with a crocodilianlike, rather than birdlike, mode of incubation and nest protection. We see little in the fossil record of dinosaur reproduction inconsistent with these animals having exhibited a crocodilian-like mode of egg incubation and of hatchling maturity. Even so, given the posthatching behavior of modern crocodilians, maternal care and protection of the young of early birds and dinosaurs cannot be ruled out.

\section{Acknowledgments}

We thank W. J. Hillenius and J. M. Starck for discussion, comments, and suggestions regarding this manuscript; J. W. Hicks and A. F. Bennett for inviting us to submit this manuscript; and two anonymous reviewers for their suggestions and comments. Some sections of this manuscript were modified from Jones and Ruben (2001).

\section{Literature Cited}

Avery R.A. 1982. Field studies of body temperatures and thermoregulation. Pp. 93-166 in C. Gans and H.F. Pough, eds. Biology of the Reptilia. Vol. 12. Academic Press, London.
Baker M.A. 1982. Brain cooling in endotherms in heat and exercise. Annu Rev Physiol 44:85-96.

Bakker R.T. 1968. The superiority of dinosaurs. Discovery 3: $11-22$.

1971. Dinosaur physiology and the origin of mammals. Evolution 25:636-658.

. 1975. Dinosaur renaissance. Sci Am 232:58-78.

. 1980. Dinosaur heresy-dinosaur renaissance. Pp. 351-462 in R.D.K. Thomas and E.C. Olson, eds. A Cold Look at Warmblooded Dinosaurs. Westview, Boulder, Colo.

_. 1986. The Dinosaur Heresies. Morrow, New York.

Bang B. 1971. Functional anatomy of the olfactory system in 23 orders of birds. Acta Anat (Basel) 79:1-71.

Barrick R.E. and W.J. Showers. 1994. Thermophysiology of Tyrannosaurus rex: evidence from oxygen isotopes. Science 265:222-224.

Barsbold R. 1983. Carnivorous dinosaurs from the Cretaceous of Mongolia: the joint Soviet-Mongolian palaeontological expedition. Transactions 19:1-117.

Bellairs A.D.A. and C.R. Jenkin. 1960. The skeleton of birds. Pp. 241-300 in A.J. Marshall, ed. Biology and Comparative Physiology of Birds. Academic Press, New York.

Bennett A.F. 1973a. Blood physiology and oxygen transport during activity in two lizards, Varanus gouldii and Sauromalus hispidus. Comp Biochem Physiol 46A:673-690.

- $1973 b$. Ventilation in two species of lizards during rest and activity. Comp Biochem Physiol 46A:653-671.

. 1982. The energetics of reptilian activity. Pp. 155-199 in C. Gans and H.F. Pough, eds. Biology of the Reptilia. Vol. 13. Academic Press, New York.

- 1991. The evolution of activity capacity. J Exp Biol 160:1-23.

Bennett A.F. and B. Dalzell. 1973. Dinosaur physiology: a critique. Evolution 27:170-174.

Bennett A.F. and W.R. Dawson. 1976. Metabolism. Pp. 127-223 in C. Gans and W.R. Dawson, eds. Biology of the Reptilia. Vol. 5. Academic Press, New York.

Bennett A.F. and J.A. Ruben. 1979. Endothermy and activity in vertebrates. Science 206:649-654.

Bennett A.F., R.S. Seymour, and G.J.W. Webb. 1985. Massdependence of anaerobic metabolism and acid-base disturbance during activity in the salt-water crocodile, Crocodylus porosus. J Exp Biol 118:161-171.

Bernstein M.H., et al. 1984. Extrapulmonary gas exchange enhances brain oxygen in pigeons. Science 226:564-566.

Brackenbury J.H. 1987. Ventilation of the lung-air sac system. Pp. 36-69 in T.J. Sellers, ed. Bird Respiration. CRC, Boca Raton, Fla.

Britt B.B., P.J. Makovicky, J. Gauthier, and N. Bonde. 1998. Postcranial pneumatization in Archaeopteryx. Nature 395: 374-376.

Brooke M. and T.R. Birkhead. 1991. The Cambridge Encyclo- 
pedia of Ornithology. Cambridge University Press, Cambridge.

Burnham D.A., K.L. Derstler, P.J. Currie, R.T. Bakker, Z.-H. Zhou, and J.H. Ostrom. 2000. Remarkable new birdlike dinosaur (Theropoda: Maniraptora) from the Upper Cretaceous of Montana. Univ Kans Paleontol Contrib 13:1-14.

Carrier D.R. and C.G. Farmer. 2000a. The evolution of pelvic aspiration in archosaurs. Paleobiology 26:271-293.

- $2000 \mathrm{~b}$. The integration of ventilation on locomotion in archosaurs. Am Zool 40:87-100.

Case T.J. 1978. On the evolution and adaptive significance of postnatal growth rates in terrestrial vertebrates. Q Rev Biol 53:243-282.

Chatterjee S. 1997. The beginnings of avian flight. Pp. 311-335 in Dinofest International: Proceedings of a Symposium Sponsored by Arizona State University. Academy of Natural Sciences, Philadelphia.

Chen P.-J., Z.-M. Dong, and S.-N. Zhen. 1998. An exceptionally well-preserved theropod dinosaur from the Yixian Formation of China. Nature 391:147-52.

Chinsamy A. 1994. Dinosaur bone histology: implications and inferences. Pp. 317-323 in G.D. Rosenberg and D. Wolberg, eds. Dinofest: Paleontological Society Special Publication. No. 7. University of Tennessee Press, Knoxville.

Chinsamy A., L.M. Chiappe, and P. Dodson. 1994. Growth rings in Mesozoic birds. Nature 368:196-197.

Chinsamy A. and P. Dodson. 1995. Inside a dinosaur bone. Am Sci 83:174-180.

Chinsamy A. and W.J. Hillenius. In press. Physiology of nonavian dinosaurs. In D.B. Weishampel et al., eds. The Dinosauria. University of California Press, Berkeley.

Clark J.M., M.A. Norell, and L.M. Chiappe. 1999. An oviraptorid skeleton from the Late Cretaceous of Ukhaa Tolgod, Mongolia, preserved in an avian-like brooding position over an oviraptorid nest. Am Mus Novit 3265:1-35.

Colbert E.H. and C.C. Mook. 1951. The ancestral crocodilian Protosuchus. Bull Am Mus Nat Hist 97:143-182.

Coombs, W.P. 1989. Modern analogs for dinosaur nesting and parental behavior. Pp. 21-53 in J.O. Farlow, ed. Paleobiology of the Dinosaurs. Books on Demand, Boulder, Colo.

Coombs W.P., Jr., and T. Maryanska. 1990. Ankylosauria. Pp. 456-483 in D.B. Weishampel et al., eds. The Dinosauria. University of California Press, Berkeley.

Cott H.B. 1961. Scientific results of an inquiry into the ecology and economic status of the Nile crocodile (Crocodylus niloticus) in Uganda and Northern Rhodesia. Trans Zool Soc Lond 29:211-357.

- 1971. Parental care in the Crocodilia, with special reference to Crocodylus niloticus in Crocodiles. Proceedings of the First Meeting of Crocodile Specialists, Switzerland. International Union for the Conservation of Nature and Natural Resources. Pp. 166-180.
Crush P.J. 1984. A Late Upper Triassic Sphenosuchid crocodilian from Wales. Palaeontology 27:131-157.

Currie P.J. 1997. Theropoda. Pp. 731-737 in P.J. Currie and K. Padian, eds. Encyclopedia of Dinosaurs. Academic Press, San Diego, Calif.

Dal Sasso C. and M. Signore. 1998a. Exceptional soft-tissue preservation in a theropod dinosaur from Italy. Nature 392: 383-387.

1998b. In situ preservation in Scipionyx. P. 23 in J.W.M. Jagt et al., eds. Third European Workshop of Vertebrate Paleontology-Maastricht. Naturhistorisches Museum, Maastricht.

Darveau C.-A., R.K. Suarez, R.D. Andrews, and P.W. Hochachka. 2002. Allometric cascade as a unifying principle of body mass effects on metabolism. Nature 417:166-170.

Dietz M.W. and R.H. Drent. 1997. Effect of growth rate and body mass on resting metabolic rate in galliform chicks. Physiol Zool 70:493-501.

Dodson P. 2000. Origin of birds: the final solution? Am Zool 40:504-512.

Dodson P. and P.J. Currie. 1990. Neoceratopsia. Pp. 593-618 in D.B. Weishampel et al., eds. The Dinosauria. University of California Press, Los Angeles.

Dong Z.-M. and P.J. Currie. 1998. On the discovery of an oviraptorid skeleton on a nest of eggs at Bayan Mandahu, Inner Mongolia, People's Republic of China. Can J Earth Sci 33:631-636.

Drent R. 1972. The natural history of incubation. Pp. 262-311 in D.S. Farner, ed. Breeding Biology of Birds. National Academy of Sciences, Washington, D.C.

Duncker H.-R. 1971. The lung air sac system of birds. Adv Anat Embryol Cell Biol 45:1-171.

- 1972. Structure of avian lungs. Respir Physiol 14: 44-63.

. 1974. Structure of the avian respiratory tract. Respir Physiol 22:1-19.

- 1978. General morphological principles of amniote lungs. Pp. 2-15 in J. Piiper, ed. Respiratory Function in Birds, Adult and Embryonic. Springer, Berlin.

. 1989. The lung air sac system of birds. Pp. 39-67 in A.S. King and J. McLelland, eds. Form and Function in Birds. Vol. 1. Academic Press, New York.

Else P.L. and A.J. Hulbert. 1981. Comparison of the "mammal machine" and the "reptile machine": energy production. Am J Physiol 240:R3-R9.

Farlow J.O. 1990. Dinosaur energetics and thermal biology. Pp. 43-55 in D.B. Weishampel et al., eds. The Dinosauria. University of California Press, Berkeley.

Farlow J.O., P. Dodson, and A. Chinsamy. 1995. Dinosaur biology. Annu Rev Ecol Syst 26:445-471.

Farmer C.G. and D.R. Carrier. 2000a. Pelvic aspiration in the American alligator (Alligator mississippiensis). J Exp Biol 203: 1679-1687. 
- 2000b. Ventilation and gas exchange during treadmill locomotion in the American alligator (Alligator mississippiensis). J Exp Biol 203:1671-1678.

Fedde M.R. 1987. Respiratory muscles. Pp. 3-37 in T.J. Sellers, ed. Bird Respiration. Vol. 1. CRC, Boca Raton, Fla.

Feduccia A. 1999a. 1,2,3 = 2,3,4: accommodating the cladogram. Proc Natl Acad Sci USA 96:4740-4742.

1999b. The Origin and Evolution of Birds. 2d ed. Yale University Press, New Haven, Conn.

Fisher P.E., D.A. Russell, M.K. Stoskopf, R.E. Barrick, M. Hammer, and A.A. Kuzmitz. 2000. Cardiovascular evidence for an intermediate or higher metabolic state in an ornithischian dinosaur. Science 288:503-505.

Forster C.A. 1990. The postcranial skeleton of the ornithopod dinosaur Tenontosaurus tilletti. J Vertebr Paleontol 10: 273-294.

Frair W., R.G. Ackman, and Mrosovsky. 1972. Body temperature of Dermochelys coriacea: warm turtle from cold water. Science 177:791-793.

Franklin C., F. Seebacher, G.C. Grigg, and M. Axelsson. 2000. At the crocodilian heart of the matter. Science 289: 1687-1688.

Frey E. 1988. The carrying system of crocodilians: a biomechanical and phylogenetic analysis. Stuttg Beitr Naturk A 426: $1-60$.

Gans C. 1996. An overview of parental care among the Reptilia. Adv Study Behav 25:145-157.

Gans C. and B. Clark. 1976. Studies on the ventilation of Caiman crocodilus (Reptilia: Crocodilia). Respir Physiol 26: 285-301.

Geist N.R. 2000. Nasal respiratory turbinate function in birds. Physiol Biochem Zool 73:581-589.

Geist N.R. and A. Feduccia. 2000. Gravity-defying behaviors: identifying models for protoaves. Am Zool 40:664-675.

Geist N.R. and T.D. Jones. 1996. Juvenile skeletal structure and the reproductive habits of dinosaurs. Science 272:712-714.

Gill F.B. 1994. Ornithology. 2d ed. W.H. Freeman, New York.

Goodrich E.S. 1930. Studies on the structure and development of vertebrates. Macmillan, London.

Greenberg N. 1980. Physiological and behavioral thermoregulation in living reptiles. Pp. 141-166 in R.D.K. Thomas and E.C. Olson, eds. A Cold Look at the Warmblooded Dinosaurs. Westview, Boulder, Colo.

Gregory W.K. 1951. Evolution Emerging. Macmillan, New York.

Grenard S. 1991. Handbook of Alligators and Crocodiles. Krieger, Malabar, Fla.

Hamilton W.J. and F. Heppner. 1966. Radiant solar energy and the function of black homeotherm pigmentation: an hypothesis. Science 155:196-197.

Harwell A., D. van Leer, and J.A. Ruben. 2002. New evidence for hepatic-piston breathing in theropods. J Vertebr Paleontol 22:63A.

Hemmingsen A.M. 1960. Energy metabolism as related to body size and respiratory surfaces, and its evolution. Rep Steno Mem Hospital 9:7-110.

Hengst R. 1998. Ventilation and gas exchange in theropod dinosaurs. Science 281:47-48.

Hicks J.W. and C.G. Farmer. 1998. Ventilation and gas exchange in theropod dinosaurs. Science 281:47-48.

- 1999. Gas exchange potential in reptilian lungs: implications for the dinosaur-avian connection. Respir Physiol 117:73-83.

Hildebrand M. and G.E. Goslow, Jr. 2001. Analysis of Vertebrate Structure. Wiley, New York.

Hillenius W.J. 1992. The evolution of nasal turbinates and mammalian endothermy. Paleobiology 18:17-29.

- 1994. Turbinates in therapsids: evidence for Late Permian origins of mammalian endothermy. Evolution 48: 207-229.

Hofstetter R. and J.-P. Gasc. 1969. Vertebrae and ribs of modern reptiles. Pp. 201-310 in C. Gans et al., eds. Biology of the Reptilia. Vol. 1, Morphology A. Academic Press, London.

Horner C.C., J.R. Horner, and D.B. Weishampel. 2001a. Comparative internal cranial morphology of some hadrosaurian dinosaurs using computerized tomographic X-ray analysis and rapid prototyping. J Vertebr Paleontol 21:64A.

Horner J.R. 2000. Dinosaur reproduction and parenting. Annu Rev Earth Planet Sci 28:19-45.

Horner J.R., A.J. de Ricqles, and K. Padian. 2000. Long bone histology of the hadrosaurid dinosaur Maisaura peeblesorum: growth dynamics and physiology based on an ontogenetic series of skeletal elements. J Vertebr Paleontol 20:115-129.

Horner J.R., K. Padian, and A.J. de Ricqles. 2001b. Comparative osteohistology of some embryonic and perinatal archosaurs: developmental and behavioral implications for dinosaurs. Paleobiology 27:39-58.

Hutchinson J.R. 2001. The evolution of pelvic osteology and soft tissues on the line to extant birds (Neorithes). Zool J Linn Soc 131:123-168.

Ingelstedt S. 1956. Studies on the conditioning of air in the respiratory tract. Acta Oto-Laryngol 131:1-79.

Jackson D.C. and K. Schmidt-Neilsen. 1964. Countercurrent heat exchange in the respiratory passages. Proc Natl Acad Sci USA 51:1192-1197.

Jones T.D. and J.A. Ruben. 2001. Respiratory structure and function in theropod dinosaurs and some related taxa. Pp. 443-461 in J. Gauthier and L.F. Gall, eds. Proceedings of the International Symposium in Honor of John H. Ostrom (February 13-14, 1999): New Perspectives on the Origins and Evolution of Birds. Yale University Press, New Haven, Conn. Jones T.D., J.A. Ruben, P.F.A. Maderson, and L.D. Martin. 2001. Longisquama fossil and feather morphology. Science 291: 1899-1902.

Jones T.D., J.A. Ruben, L.D. Martin, E.N. Kurochkin, A. Feduccia, P.F.A. Maderson, W.J. Hillenius, N.R. Geist, and V. 
Alifanov. 2000. Nonavian feathers in a Late Triassic Archosaur. Science 288:2202-2205.

Kemp T.S. 1988. Haeomothermia or Archosauria? the interrelationships of mammals, birds, and crocodiles. Biol J Linn Soc 92:67-104.

King A.S. 1966. Structural and functional aspects of the avian lung and air sacs. Int Rev Gen Exp Zool 2:171-267.

King A.S. and D.Z. King. 1979. Avian morphology. Pp. 1-38 in A.S. King and MacLelland, eds. Form and Function in Birds. Academic Press, London.

Kolodny Y., B. Lutz, M. Sander, and W.A. Clemens. 1996. Dinosaur bones: fossils or pseudomorphs? the pitfalls of physiology reconstruction from apatitic fossils. Palaeogeogr Palaeoclimatol Palaeoecol 126:161-167.

Lang J.W. 1989. Social behavior. Pp. 102-117 in C.A. Ross, ed. Crocodiles and Alligators. Facts-on-File, New York.

Lustick S., S. Talbot, and E. Fox. 1970. Absorption of radiant energy in red-winged blackbirds (Agelaius phoeniceus). Condor 72:471-473.

Maina J.N. and M. Africa. 2000. Inspiratory aerodynamic valving in the avian lung: functional morphology of the extrapulmonary primary bronchus. J Exp Biol 203:2865-2876.

Marsh O.C. 1883. Principal characters of American Jurassic dinosaurs. VI. Restoration of Brontosaurus. Am J Sci 26: 81-85.

Martill D.M., E. Frey, H.-D. Sues, and A.R.I. Cruickshank. 2000. Skeletal remains of a small theropod dinosaur with associated soft structures from the Lower Cretaceous Santana Formation of northeastern Brazil. Can J Earth Sci 37:891-900.

Martin L.D. 1991. Mesozoic birds and the origin of birds. Pp. 485-540 in H.-P. Schultze and L. Trueb, eds. Origins of the Higher Groups of Tetrapods: Controversy and Consensus. Comstock, Ithaca, N.Y.

Martoff B.S., W.M. Palmer, J.R. Bailey, and J.R.I. Harrison. 1980. Amphibians and Reptiles of the Carolinas and Virginia. University of North Carolina Press, Chapel Hill.

Maryanska T., H. Osmólska, and M. Wolsan. 2002. Avialan status for Oviraptorosauria. Acta Palaeontol Pol 47:97-116.

McIntosh J.S. 1990. Sauropoda. Pp. 345-401 in D.B. Weishampel et al., eds. The Dinosauria. University of California Press, Berkeley.

McLelland J. 1989. Anatomy of lungs and air sacs. Pp. 221-279 in A.S. King and J. McLelland, eds. Form and Function in Birds. Vol. 4. Academic Press, London.

McNab B.K. and W.A. Auffenberg. 1976. The effect of large body size on temperature regulation of the Komodo dragon, Varanus komodoensis. Comp Biochem Physiol 55A:345-350.

Nagy K.A. 1987. Field metabolic rates and food requirement scaling in mammals and birds. Ecol Monogr 57:111-128.

Norell M. and J.M. Clark. 1996. Dinosaurs and their youth. Science 273:165-168.

Norell M.A. 1995. Origins of the feathered nest. Nat Hist 104: 58-61.
Norell M.A., J.M. Clark, L.M. Chiappe, and D. Dashzeveg. 1995. A nesting dinosaur. Nature 378:774-776.

Norell M.A. and P.J. Makovicky. 1997. Important features of the dromaeosaur skeleton: information from a new specimen. Am Mus Novit 3215:1-28.

1999. Important features of the dromaeosaur skeleton. II. Information from newly collected specimens of Velociraptor mongoliensis. Am Mus Novit 3282:1-44.

Norman D.B. 1980. On the ornithischian dinosaur Iguanodon bernissartensis from the Lower Cretaceous of Bernissart (Belgium). Inst R Sci Nat Belg Mem 178:1-103.

Novas F.E. 1993. New information on the systematics and postcranial skeleton of Herrerasaurus ischigualastensis (Theropoda: Herrerasauridae) from the Ischigualasto formation (Upper Triassic) of Argentina. J Vertebr Paleontol 13: 400-423.

O'Conner M.P. and P. Dodson. 1999. Biophysical constraints on the thermal ecology of dinosaurs. Paleobiology 25: 341-368.

Ohmart R.D. and R.C. Lasiewski. 1971. Roadrunners: energy conservation by hypothermia and absorption of sunlight. Science 172:67-69.

Olson J.M. 1992. Growth, the development of endothermy, and the allocation of energy in red-winged blackbirds (Agelaius pheoniceus) during the nestling period. Physiol Zool 65: 125-152.

Ostrom J.H. 1969. A new theropod dinosaur from the Lower Cretaceous of Montana. Postilla 128:1-17.

. 1991. The question of the origin of birds. Pp. 467-484 in H.-P. Schultze and L. Trueb, eds. Origins of the Higher Groups of Tetrapods: Controversy and Consensus. Comstock, Ithaca, N.Y.

Padian K. and J.R. Horner. 2002. Typology versus transformation in the origin of birds. Trends Ecol Evol 17:120-124.

Paladino F.V., M.P. O’Conner, and J.R. Spotila. 1990. Metabolism of leatherback turtles, gigantothermy, and thermoregulation of dinosaurs. Nature 344:858-860.

Paladino F.V., J.R. Spotila, and P. Dodson. 1997. A blueprint for giants: modeling the physiology of large dinosaurs. Pp. 491-504 in J.O. Farlow and M.K. Brett-Surnam, eds. The Complete Dinosaur. Indiana University Press, Bloomington.

Paul G.S. 2001. Were the respiratory complexes of predatory dinosaurs like crocodilians or birds? Pp. 463-482 in J. Gauthier and L.F. Gall, eds. Proceedings of the International Symposium in Honor of John H. Ostrom (February 13-14, 1999): New Perspectives on the Origins and Evolution of Birds. Yale Peabody Museum of Natural History, Yale University, New Haven, Conn.

Pearson O.P. 1954. Habits of the lizard Liolaemus multiformis multiformis at high latitudes in southern Peru. Copeia 1954: 111-116.

Perez-Moreno B.P., J.L. Sanz, A.D. Buscalioni, J.J. Moratella, F. Ortega, and D. Rasskin-Gutman. 1994. A unique multi- 
toothed ornithomimisaur dinosaur from the Lower Cretaceous of Spain. Nature 370:363-367.

Perry S.F. 1983. Reptilian lungs: functional anatomy and evolution. Adv Anat Embryol Cell Biol 79:1-83.

1989. Mainstreams in the evolution of vertebrate respiratory structures. Pp. 1-67 in A.S. King and J. McLelland, eds. Form and Function in Birds. Vol. 4. Academic Press, London.

- 1992. Gas exchange strategies in reptiles and the origin of the avian lung. Pp. 149-167 in S.C. Wood, R.E. Weber, A.R. Hargens, and R.W. Millard, eds. Physiological Adaptations in Vertebrates: Respiration, Circulation, and Metabolism. Marcel Dekker, New York.

-2001. Functional morphology of the reptilian and avian respiratory systems and its implications for theropod dinosaurs. Pp. 429-441 in J. Gauthier and L.F. Gall, eds. Proceedings of the International Symposium in Honor of John H. Ostrom (February 13-14, 1999): New Perspectives on the Origins and Evolution of Birds. Yale Peabody Museum of Natural History, Yale University, New Haven, Conn.

Perry S.F. and H.-R. Duncker. 1980. Interrelationships of static mechanical factors and anatomical structure in lung evolution. J Comp Physiol B 138:321-334.

Perry S.F. and C. Reuter. 1999. Hypothetical lung structure of Brachiosaurus (Dinosauria: Sauropoda) based on functional constraints. Mitt Mus Nat Berl Geowissenschaftliche Reihe 2:75-79.

Peters D.S. and E. Görgner. 1992. A comparative study on the claws of Archaeopteryx. Pp. 29-37 in K. Campbell, ed. Proceedings of the Second International Symposium of Avian Paleontology. L. A. Museum of Natural History Press, Los Angeles.

Pough F.H., R.M. Andrews, J.E. Cadle, M.L. Crump, A.H. Savitzky, and K.D. Wells. 1998. Herpetology. Prentice Hall, Upper Saddle River, N.J.

Proctor D.F., I. Andersen, and G.R. Lundqvist. 1977. Human nasal mucosal function at controlled temperatures. Respir Physiol 30:109-124.

Prum R.O. 2001. Longisquama fossil and feather morphology. Science 291:1899-1900.

Randall D., W.W. Burggren, and K. French. 2002. Eckert's animal physiology: mechanisms and adaptations. 5th ed. W.H. Freeman, New York.

Randolph S.E. 1994. The relative timing of the origin of flight and endothermy: evidence from the comparative biology of birds and mammals. Zool J Linn Soc 112:389-97.

Reid R.E.H. 1997. Dinosaurian physiology: the case for "intermediate" physiology. Pp. 449-473 in J.O. Farlow and M.K. Brett-Surnam, eds. The Complete Dinosaur. Indiana University Press, Bloomington.

Ricklefs R.E. 1979. Adaptation, constraint, and compromise in avian post-natal development. Biol Rev Camb Philos Soc 54: 269-290.
Romer A.S. 1956. Osteology of the Reptiles. University of Chicago Press, Chicago.

Rowe T., E.F. McBride, and P.C. Sereno. 2001. Dinosaur with a heart of stone. Science 291:783.

Royer D.L., C.P. Osborne, and D.J. Beerling. 2002. High CO2 increases the freezing sensitivity of plants: implications for paleoclimatic reconstructions from fossil floras. Geology 30: 963-966.

Ruben J.A. 1991. Reptilian physiology and the flight capacity of Archaeopteryx. Evolution 45:1-17.

- 1995. The evolution of endothermy in mammals and birds: from physiology to fossils. Annu Rev Physiol 57:69-95.

- 1996. Evolution of endothermy in mammals, birds and their ancestors. Pp. 347-376 in I.A. Johnston and A.F. Bennett, eds. Animals and Temperature: Phenotypic and Evolutionary Adaptation. Cambridge University Press, Cambridge.

Ruben J.A., C. Dal Sasso, N.R. Geist, W.J. Hillenius, T.D. Jones, and M. Signore. 1999. Pulmonary function and metabolic physiology of theropod dinosaurs. Science 283:514-516.

Ruben J.A., W.J. Hillenius, N.R. Geist, A. Leitch, T.D. Jones, P.J. Currie, J.R. Horner, and G. Espe III. 1996. The metabolic status of some Late Cretaceous dinosaurs. Science 273: 1204-1207.

Ruben J.A. and T.D. Jones. 2000. Selective factors for the origin of fur and feathers. Am Zool 40:585-596.

Ruben J.A., T.D. Jones, N.R. Geist, and W.J. Hillenius. 1997a. Lung structure and ventilation in theropod dinosaurs and early birds. Science 278:1267-1270.

- 1998. Ventilation and gas exchange in theropod dinosaurs. Science 281:47-48.

Ruben J.A., A. Leitch, W.J. Hillenius, N.R. Geist, and T.D. Jones. 1997b. New insights into the metabolic physiology of dinosaurs. Pp. 505-518 in J.O. Farlow and M.K. Brett-Surnam, eds. The Complete Dinosaur. Indiana University Press, Bloomington.

Ruxton G.D. 2000. Statistical power analysis: application to an investigation of dinosaur thermal physiology. J Zool 252: 239-241.

Scheid P. and J. Piiper. 1989. Respiratory mechanics and air flow in birds. Pp. 369-388 in A.S. King and J. McLelland, eds. Form and Function in Birds. Vol. 4. Academic Press, New York.

Schmidt-Neilsen K. 1971. How birds breathe. Sci Am 225: 72-79.

- 1984. Scaling. Cambridge University Press, Cambridge.

- 1990. Animal Physiology: Adaptation and Environment. 4th ed. Cambridge University Press, Cambridge.

Seebacher F., G.C. Grigg, and L.A. Beard. 1999. Crocodiles as dinosaurs: behavioural thermoregulation in very large ectotherms leads to high and stable body temperatures. J Exp Biol 202:77-86.

Sereno P.C. and S. Chao. 1988. Psittacosaurus meileyingensis 
(Ornithischia: Ceratopsia), a new psittacosaur from the Lower Cretaceous of northeastern China. J Vertebr Paleontol 8:353-365.

Seymour R.S. 1979. Dinosaur eggs: gas conductance through the shell, water loss during incubation and clutch size. $\mathrm{Pa}$ leobiology 5:1-11.

Shine R. 1988. Parental care in reptiles. Pp. 275-329 in C. Gans and R.B. Huey, eds. Biology of the Reptilia. Liss, New York. Spotila J.R., M.P. O'Conner, P. Dodson, and F.V. Paladino. 1991. Hot and cold running dinosaurs: body size, metabolism and migration. Mod Geol 16:203-227.

Standora E.A., J.R. Spotila, J.A. Keinath, and C.R. Shoop. 1984. Body temperatures, diving cycles, and movement in the subadult leatherback turtle, Dermochelys coriacea. Herpetologica 40:169-176.

Starck J.M. 1996. Comparative morphology and cytokinetics of skeletal growth in hatchlings of altricial and precocial birds. Zool Anz 235:53-75.

Starck J.M. and A. Chinsamy. 2002. Bone microstructure and developmental plasticity in birds and other dinosaurs. J Morphol 254:232-246.

Thomas D.W., C. Bosque, and A. Arends. 1993. Development of thermoregulation and energetics of nestling oilbirds (Steatornis caripensis). Physiol Zool 66:322-348.

Upchurch P. 1995. The evolutionary history of sauropod dinosaurs. Philos Trans R Soc Lond B Biol Sci 349:365-390.

Varricchio D.J., F. Jackson, J.J. Borkowski, and J.R. Horner. 1997. Nest and egg clutches of the dinosaur Troodon formosus and the evolution of avian reproductive traits. Nature 385: 247-250.

Visser G.H. and R.E. Ricklefs. 1993. Development of temperature regulation in shorebirds. Physiol Zool 66:771-792.

von Koenigswald W., G. Storch, and G. Richter. 1988. Ursprüngliche "Insectenfresser," extravagante Igel und Langfinger. Pp. 159-177 in Schaal and W. Zeigler, eds. Messel: ein Schaufenster in die Geschichte der Erde und des Lebens. Waldemar Kramer, Frankfurt.

Weishampel D.B. 1981a. Acoustic analysis of potential vocali- zation in lambeosaurine dinosaurs (Reptilia: Ornithischia). Paleobiology 7:252-261.

- 1981b. The nasal cavity of lambeosaurine hadrosaurids (Reptilia: Ornithischia). J Paleontol 55:1046-1057.

- 1997. Dinosaurian cacophony. BioSci 47:150-159.

Weishampel D.B., D.B. Norman, and D. Grigorescu. 1993. Telmatosaurus transsylvaticus from the Late Cretaceous of Romania: the most basal hadrosaurid dinosaur. Paleontology 36:361-385.

Welty J.C. and L. Baptista. 1988. The Life of Birds. Saunders College, Fort Worth, Tex.

Westoby M., M.R. Leishman, and J.M. Lord. 1995. On misinterpreting the "phylogenetic correction." J Ecol 83: 531-534.

Wettstein O. 1931. Rhynchocephalia. Pp. 1-235 in W. Kükenthal and T. Krumbach, eds. Handbuch der Zoologie. De Gruyter, Berlin.

White F.N. 1968. Functional anatomy of the heart of reptiles. Am Zool 8:211-219.

- 1976. Circulation. Pp. 275-334 in C. Gans and W.R. Dawson, eds. Biology of the Reptilia. Vol. 5. Academic Press, New York.

Witmer L.M. 1995. Homology of facial structures in extant archosaurs (birds and crocodilians), with special reference to paranasal pneumaticity and nasal conchae. J Morphol 225: 269-327.

- 1997. The evolution of the antorbital cavity of archosaurs: a study in soft-tissue reconstruction in the fossil record with an analysis of the function of pneumaticity. J Vertebr Paleontol 17:1-73.

- 1999. Nasal conchae and blood supply in some dinosaurs: physiological implications. J Vertebr Paleontol 19: $85 \mathrm{~A}$.

Xu X., Z.-L. Tang, and X.-L. Wang. 1999. A therizinosauroid dinosaur with integumentary structures from China. Nature 399:350-4.

Young C.-C. 1947. On Lufengosaurus magnus (sp. nov.) and additional finds of Lufengosaurus heunei Young. Palaeontol Sin 12:1-53. 